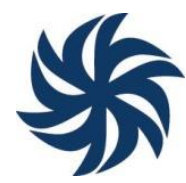

\title{
ACCIONES LEGISLATIVAS PARA ENFRENTAR LA PANDEMIA COVID- 19 EN LA REPÚBLICA DOMINICANA
}

\section{LEGISLATIVE ACTIONS TO DEAL WITH THE COVID-19 PANDEMIC IN THE DOMINICAN REPUBLIC}

\section{AÇÕES LEGISLATIVAS PARA ENFRENTAR A PANDEMIA DE COVID-19 NA REPÚBLICA DOMINICANA}

\author{
Ana Belén Benito Sánchez ${ }^{1}$ \\ Araceli Mateos Díaz ${ }^{2}$
}

\begin{abstract}
Resumen: Este trabajo analiza la actividad normativa y fiscalizadora del Congreso Nacional de la República Dominicana durante el primer Estado de Emergencia, declarado el 19 de marzo hasta el 30 de junio de 2020. Para controlar las facultades extraordinarias otorgadas al Ejecutivo, el Legislativo promulgó seis Resoluciones y una Ley, además de otras iniciativas e interpelaciones. Los datos obtenidos a partir de las páginas webs de la Presidencia, la Cámara de Diputados y del Senadoevidencian que el Estado de Emergencia no impulsó la beligerancia ni la cohesión del trabajo parlamentario de un Legislativo poco proactivo, ratificador y legimitador de la acción de gobierno.
\end{abstract}

Palabras clave: Control Parlamentario; Gestión Gubernamental; COVID-19; República Dominicana.

\begin{abstract}
This paper analyzes the regulatory and controlling activity of the National Congress of the Dominican Republic during the first state of emergency, declared on March 19 until June 30, 2020. In order to supervise the extraordinary powers granted to the Government, the Legislative branch passed six Resolutions and one Law, as well as other initiatives and parliamentary questions. Data from the websites of the Presidency, the Chamber of Deputies and the Senate, show that the State of Emergency did not promote belligerence or cohesion of parliamentary work, because of the Legislative Branch' non proactive, ratifying and legitimating nature.
\end{abstract}

Key words: Parliamentary Control; Crisis Management; COVID-19; Dominican Republic.

Resumo: Este trabalho analisa a atividade regulatória e fiscalizadora do Congresso Nacional da República Dominicana durante o primeiro Estado de Emergência, declarado em 19 de março até 30 de junho de 2020. Para controlar os poderes extraordinários conferidos ao Executivo, o Legislativo promulgou seis Resoluções e uma Lei, além de outras iniciativas e interpelações. Os dados obtidos nas páginas oficiais da Presidência, Câmara dos Deputados e Senado evidenciam que o Estado de Emergência não promoveu a beligerância nem a coesão da atividade parlamentar de um Legislativo pouco pró-ativo, ratificador e legimador de ações de governo.

Palavras-chave: Controle Parlamentar; Gestão Governamental; COVID-19; República Dominicana.

\footnotetext{
1 Profesora del Departamento de Ciencia Política y de la Administración (UCM). Doctora en Ciencia Política (USAL), con Maestrías en Administración Pública (UPR) y Estudios Latinoamericanos (USAL). Investigadora postdoctoral en el Centro de Estudios Políticos y Constitucionales (2016-2019). Código ORCID: https://orcid.org/0000-0003-0402-5419. Contacto: anabeleta@usal.es.

2 Profesora Titular del Área de Ciencia Política y de la Administración (USAL). Miembro del Instituto de Iberoamérica de la Universidad de Salamanca. Miembro del equipo editorial de las revistas América Latina Hoy, Revista Española de Ciencia Política y Revista Latinoamericana de Opinión Pública. Código ORCID: https://orcid.org/0000-0001-6208-5917. Contacto: amd@usal.es
} 


\section{Introducción}

El 16 de marzo de 2020 se registra en la República Dominicana la primera muerte por Coronavirus que, hasta la fecha, deja un balance de 240,000 positivos y 3,100 fallecidos. Dos días después del primer deceso, el Presidente Danilo Medina acude al Congreso para declarar el Estado de Emergencia Nacional, y lo hará en cinco ocasiones más para prorrogarlo hasta finales de junio, a solo cuatro días de las elecciones que han puesto fin a 16 años de dominio del Partido de la Liberación Dominicana (PLD). Tras el breve impasse electoral, Medina vuelve al Congreso el 20 de julio - esta vez como Presidente saliente- para solicitar un segundo Estado de Emergencia que gestionará la administración de Luis Abinader (2020-2024), del Partido Revolucionario Moderno (PRM), bajo la supervisión de un nuevo Hemiciclo.

La atención a las acciones del Poder Legislativo para enfrentar la pandemia en el caso dominicano, se justifica en la débil institucionalización programática de su oferta partidista y en la relación que mantiene con su contraparte el Ejecutivo. La República Dominicana es un Estado unitario, centralizado y con forma de gobierno presidencialista. La configuración del equilibrio de poderes se ha caracterizado por la preponderancia del Ejecutivo frente al Legislativo, con escasa relevancia de sus funciones propositivas y de control (MARSTEINTREDET, 2010). Una interacción que ha llevado a la literatura a ubicar el caso dominicano en la tipología de presidencialismo dominante (ZOVATTO Y OROZCO, 2008). La vinculación al territorio convierte a los legisladores dominicanos en brókeres resolutivos en su distrito, rivalizando en esta tarea con el gobernador y el alcalde. Esta dinámica de constituency service, fundamental para su supervivencia y la rendición de cuentas, relega a un segundo plano su papel de agentes propositivos en el Congreso donde han de debatirse los grandes retos de la política nacional. El resultado es un Legislativo marginal y dedicado a tareas particularistas de marcado carácter clientelar (BENITO, 2017).

En la competición política, el Índice de Estructuración Programática propuesto por Kitschelt, Hawkins, Rosas y Zechmeister (2010) que valora, entre otros aspectos, la cohesión ideológica de las fuerzas políticas y la representación sobre issues, situaba al sistema de partidos dominicano en los niveles más bajos de la Región Latinoamericana. Aunque la escala izquierdaderecha funciona como atajo informativo en el país (OTERO, MATEOS Y RIVAS, 2020), carece de contenido programático (CARLIN, SINGER Y ZECHMEISTER, 2015) y de incidencia alguna en la decisión de voto de los dominicanos (RICO Y TORCAL, 2018, p. 122). Desde la etapa caudillista, la contienda gira en torno a la capacidad para otorgar beneficios concretos en una competencia centrípeta en el espectro del centro derecha (BENITO Y LOZANO, 2012). Esta laxitud programática facilita el aliancismo de ida y vuelta, el transfuguismo entre bancadas, el personalismo en el trabajo parlamentario y el particularismo en el mandato de representación legislativa. 
Además del diseño institucional y la competición no programática, la función preventiva y limitativa del poder que asiste al Congreso frente a la gestión gubernamental de la pandemia ha estado condicionada por dos circunstancias que han minimizado, aún más, su papel poco propositivo y fiscalizador. En primer lugar, el control oficialista del 51\% de la Cámara de Diputados y del $81 \%$ del Senado, aseguraban al Gobierno un escenario amigable para refrendar las medidas adoptadas3. La segunda circunstancia tiene que ver con el calendario electoral. La campaña de las legislativas y presidenciales se desarrolló durante dos de los tres meses de vigencia del Estado de Emergencia. Esto ha provocado que los legisladores que buscaban la reelección hayan estado más ocupados en las tareas de campaña en sus provincias, delegando las labores de seguimiento en la Comisión Bilateral nombrada para este fin, y -tal como revelan los registros de asistencia- con escasa presencia en los Plenos celebrados virtualmente y en la capital.

En este trabajo de carácter exploratorio examinamos el papel del Poder Legislativo en la República Dominicana durante el primer Estado de Emergencia decretado el 19 de marzo hasta el 30 de junio de 2020 con ocasión de la crisis sanitaria. Para ello, se focaliza la atención en el conjunto de asuntos tratados en las comisiones especiales creadas ad hoc y en los plenos de ambas Cámaras para determinar: 1) su anclaje constitucional y legal, y 2) categorizar su contenido y naturaleza vinculante. Se sostiene como hipótesis que el Estado de Emergencia no ha incentivado el ejercicio de las funciones propositivas y de control de los representantes.

Con respecto a la metodología, la información utilizada para dar cuenta del tipo de actividad desarrollada ha sido obtenida a partir de las páginas webs de la Consultoría Jurídica de la Presidencia de la República, del Servicio de Información Legislativa (SIL) de la Cámara de Diputados, y de las actas de sesiones del Senado. Estos datos parten de la totalidad de la actividad desarrollada durante el periodo objeto de estudio en los distintos organismos legislativos: los Plenos de la Cámara y el Senado, y la Comisión Bicameral del Congreso encargado del seguimiento de las actuaciones y medidas adoptadas durante el Estado de Emergencia. Para llevar a cabo la medición de la actividad, y el volumen de supervisión realizada, se ha diferenciado entre los temas vinculados a hacer frente a la pandemia y aquellos de continuidad que la Cámara venía desarrollando o estaba planificado. De manera que, del total de asuntos, medidas, o resoluciones sometidas a votación y/o adoptadas durante el primer Estado de Emergencia, se ha calculado el porcentaje que representan las dedicadas a afrontar, desde el punto de vista sanitario, la COVID-19, así como las dedicadas a paliar los efectos en la situación económica del país y de la ciudadanía. Al mismo tiempo, se identificó cuáles de ellas tenían un objetivo de desarrollo normativo, de control, fiscalización o de interpelación al

\footnotetext{
${ }^{3}$ El PLD controlaba el 58\% de la Cámara. En octubre 2019 Leonel Fernández abandona la formación, crea Fuerza del Pueblo y los 27 diputados leonelistas otrora oficialistas pasan a la oposición.
} 
Ejecutivo. La excepcionalidad marcada por la pandemia dificultaba llevar a cabo una comparación de esta actividad con la de cualquier otro momento o periodo legislativo previo.

Durante los tres meses y trece días de vigencia del Estado de Excepción, el Ejecutivo promulgó veintitrés (23) decretos y presentó al Poder Legislativo siete (7) Informes de su gestión de la crisis sanitaria. El Congreso Nacional ejerció las funciones de supervisión a través de la Comisión Bicameral de Seguimiento a las Actuaciones y Medidas adoptadas durante el Estado de Emergencia, nombrada para la ocasión. En las sesiones plenarias de ambas Cámaras se llevó a cabo el control parlamentario de la actuación del Gobierno, producto del cual, se promulgaron seis (6) Resoluciones autorizando el Estado de Emergencia y sus prórrogas, y una (1) Ley de Modificación del Presupuesto General, cuyo contenido se sistematiza en los Anexos.

¿Cómo ha ejercido el Poder Legislativo las funciones normativas y de control encomendadas por la Constitución y las Leyes durante el primer Estado de Excepción? Para responder a esta pregunta el artículo se organiza en cuatro secciones. Tras esta introducción en la que se identifican los condiconantes institucionales, partidistas y electorales, se presenta la producción normativa del Ejecutivo y se clasifican las acciones prescritas en los decretos promulgados para gestionar durante la pandemia la política sanitaria, laboral y económica. En la sección tercera, se analiza la actividad normativa y de control del Poder Legislativo en los respectivos plenos del Senado y la Cámara de Diputados. Por último, a modo de conclusión, se reflexiona sobre el papel del Legislativo Dominicano como instancia ratificadora y legimitadora de la acción de gobierno.

\section{Acciones del Poder Ejecutivo para enfrentar la crisis}

Desde el 19 de marzo al 30 de junio de 2020, el Ejecutivo promulgó 23 decretos para prevenir y reparar las consecuencias económicas, laborales y sanitarias de la pandemia:

- Declarar y prorrogar el Estado de Emergencia: El Ejecutivo convalidó en el Congreso sus facultades extraordinarias y remitió los Informes periódicos a la Comisión Bilateral (No.134-20; No.148-20; No.152-20; No.160-20; No.18720; No.213-20).

- Establecer el organigrama institucional de gestión de la crisis: El titular del Ministerio de la Presidencia, Gustavo Montalvo, asumió la dirección de la gestión gubernamental durante la emergencia nacional. Se crea la Comisión de Alto Nivel para la Prevención y Control del Coronavirus, con funciones directivas, además de una Comisión para Asuntos Económicos y de Empleo, y otra para los Asuntos Sociales, con participación de los ministros del ramo y organismos con competencias en la materia (No.133-20). Se conformó un 
Comité de Emergencia y Gestión Sanitaria (No.141-20), y fueron nombrados dos viceministros de Salud Pública (No. 152-20).

- Restringir derechos y libertades fundamentales: Se restringió la libertad de movimiento, reunión y asociación. Se fijó un toque de queda de 5:00pm a 6:00am y medidas para asegurar el distanciamiento social (No.135-20; No.13620; No.138-20; No.142-20; No.151-20; No.154-20; No.161-20; No.188-20). La Junta Central Electoral (JCE) suspendió la celebración de las elecciones generales previstas para el 16 de mayo y fijó la nueva cita el 5 de julio. Las restricciones impuestas coartaron el proselitismo de los candidatos en campaña (No.214-20), pero no así el de las autoridades gestionando los $\mathrm{RD} \$ 57,000$ millones destinados a la pandemia. Una desventaja en la competición que fue denunciada por la oposición.

- Adaptar los procesos administrativos a la situación de emergencia: Se suspendieron los plazos administrativos (No.137-20), se flexibilizaron los protocolos de compras indispensables para enfrentar la pandemia y se amplió el número de instituciones licitadoras (No.133-20; No144-20). La presión ciudadana ante la corrupción destapada en el Instituto Nacional de Atención Integral a la Primera Infancia (INAIPI) en las primeras semanas de la pandemia, llevó al Ejecutivo a nombrar una Comisión de Veeduría Ciudadana para vigilar las compras durante el Estado de Emergencia (No.145-20).

- Reforzar la protección social y laboral: Se crea el Fondo de Asistencia Solidaria al Empleado (FASE) para apoyar a los empleados cesados por las medidas de distanciamiento ordenadas por el Gobierno (No.134-20; No.143-20); se implementan los programas «Pá Tí» para asalariados y autónomos, y «Quédate en Casa» para trabajadores informales, que representan más del 50\% de la mano de obra. Con estas medidas, un millón y medio de hogares recibieron subsidios para afrontar las necesidades básicas.

El Ministerio de la Presidencia se erigió en jefe departamental responsable de la operacionalización y ejecución de la política pública durante la pandemia, convirtiéndose de facto en la cartera más importante del gabinete (MARTÍNEZ-GALLARDO, 2010; BLONDEL Y THIEBAULT, 1991). Una visibilidad estratégica que en otros escenarios hubiese acaparado el primer mandatario, pero que dada su imposibilidad para reelegirse, optó por apoyar en las calles al candidato oficialista en su campaña electoral. 
Tabla 1 - Decretos del Ejecutivo promulgados durante el Estado de Emergencia

$(19 / 03 / 2020$ al 30/06/2020)

\begin{tabular}{|c|c|}
\hline Decreto & Medidas adoptadas \\
\hline $\begin{array}{l}\text { No.132-20 } \\
19 / 03 / 2020\end{array}$ & $\begin{array}{l}\text { Designación de Comisión de Alto Nivel para la Prevención y Control del } \\
\text { Coronavirus, Comisión de Asuntos Económicos y de Empleo y Comisión } \\
\text { de Asuntos Sociales. }\end{array}$ \\
\hline $\begin{array}{l}\text { No.133-20 } \\
19 / 03 / 2020\end{array}$ & $\begin{array}{l}\text { Ampliación del número de organismos que pueden realizar compras y } \\
\text { contrataciones indispensables para dar respuesta al Coronavirus. }\end{array}$ \\
\hline $\begin{array}{l}\text { No. } 134-20 \\
19 / 03 / 2020\end{array}$ & $\begin{array}{l}\text { Declaración Estado de Emergencia por } 25 \text { días. Remisión Informes } \\
\text { Comisión Bicameral. } \\
\text { Restricciones al tránsito, asociación, y reunión. } \\
\text { Garantizar provisiones centros de salud, proteger el empleo y los ingresos } \\
\text { de trabajadores. }\end{array}$ \\
\hline $\begin{array}{l}\text { No.135-20 } \\
20 / 03 / 2020\end{array}$ & $\begin{array}{l}\text { Toque de queda territorio nacional. Prohibición tránsito y circulación de } \\
\text { 8:00 p.m. a 6:00 a.m. }\end{array}$ \\
\hline $\begin{array}{l}\text { No.136-20 } \\
23 / 03 / 2020\end{array}$ & $\begin{array}{l}\text { Permitir duante el toque de queda la circulación del transporte de } \\
\text { mercancías, insumos médicos y combustible, de empresas prestadoras de } \\
\text { servicios de energía, agua y servicios funerarios. }\end{array}$ \\
\hline $\begin{array}{l}\text { No.137-20 } \\
23 / 03 / 2020\end{array}$ & $\begin{array}{l}\text { Suspensión cómputo plazos y términos de procedimientos administrativos } \\
\text { en la Administración Pública durante el Estado de Emergencia. }\end{array}$ \\
\hline $\begin{array}{l}\text { No.138-20 } \\
26 / 03 / 2020\end{array}$ & Extensión horario toque de queda, de 5:00 pm a 6:00 am. \\
\hline $\begin{array}{l}\text { No. } 141-20 \\
01 / 04 / 2020\end{array}$ & $\begin{array}{l}\text { Designación Comité de Emergencia y Gestión Sanitaria para el Combate } \\
\text { del Coronavirus. }\end{array}$ \\
\hline $\begin{array}{l}\text { No.142-20 } \\
01 / 04 / 2020\end{array}$ & $\begin{array}{l}\text { Mantenimiento medidas de distanciamiento social y extensión del toque } \\
\text { de queda. }\end{array}$ \\
\hline $\begin{array}{l}\text { No.143-20 } \\
02 / 04 / 2020\end{array}$ & $\begin{array}{l}\text { Creación Fondo de Asistencia Solidaria al Empleado (FASE) durante } 60 \\
\text { días. }\end{array}$ \\
\hline $\begin{array}{l}\text { No. } 144-20 \\
02 / 04 / 2020\end{array}$ & $\begin{array}{l}\text { Ampliación organismos que pueden realizar compras y contrataciones } \\
\text { indispensables para dar respuesta al Coronavirus: Plan de Asistencia Social de } \\
\text { la Presidencia, Comedores Económicos del Estado y Instituto Nacional de } \\
\text { Atención a la Primera Infancia. }\end{array}$ \\
\hline $\begin{array}{l}\text { No. } 145-20 \\
05 / 04 / 2020\end{array}$ & $\begin{array}{l}\text { Designación Comisión de Veeduría Ciudadana para monitorizar compras y } \\
\text { contrataciones durante el Estado de Emergencia. Exigencia a la Contraloría } \\
\text { cumplir su función de control interno. }\end{array}$ \\
\hline $\begin{array}{l}\text { No.148-20 } \\
13 / 04 / 2020\end{array}$ & Prórroga Estado de Emergencia por un plazo de 17 días. \\
\hline $\begin{array}{l}\text { No.151-20 } \\
17 / 04 / 2020\end{array}$ & $\begin{array}{l}\text { Mantenimiento medidas distanciamiento social y medidas adicionales. } \\
\text { Extensión toque de queda de 5:00 pm a 6:00 am hasta el } 30 \text { de abril. }\end{array}$ \\
\hline $\begin{array}{l}\text { No.152-20 } \\
17 / 04 / 2020\end{array}$ & $\begin{array}{l}\text { Nombramiento Viceministros de Salud Pública: Dr. B. Peña y el Dr. A. } \\
\text { Puello Guerrero }\end{array}$ \\
\hline $\begin{array}{l}\text { No. } 152-20 \\
30 / 04 / 2020\end{array}$ & $\begin{array}{l}\text { Prórroga Estado de Emergencia por } 17 \text { días. Remisión Informes a Comisión } \\
\text { Bicameral. }\end{array}$ \\
\hline $\begin{array}{c}\text { No. } 154-20 \\
30 / 04 / 20\end{array}$ & $\begin{array}{l}\text { Mantenimiento distancia social, medidas adicionales y extensión toque de } \\
\text { queda de 5:00 pm a 6:00 am hasta el } 17 \text { de mayo. }\end{array}$ \\
\hline $\begin{array}{l}\text { No.160-20 } \\
16 / 05 / 2020\end{array}$ & $\begin{array}{l}\text { Prórroga Estado de Emergencia por } 15 \text { días. Remisión Informes a Comisión } \\
\text { Bicameral. }\end{array}$ \\
\hline $\begin{array}{l}\text { No. } 161-20 \\
17 / 05 / 2020\end{array}$ & $\begin{array}{l}\text { Mantenimiento medidas de distanciamiento social. Extensión toque de } \\
\text { queda hasta el } 1 \text { de junio de lunes a sábado de 7:00 p.m. a 5:00 a.m. y los } \\
\text { domingos de 5:00 p.m. a 5:00 a.m. }\end{array}$ \\
\hline $\begin{array}{l}\text { No. } 187-20 \\
01 / 06 / 2020\end{array}$ & \\
\hline
\end{tabular}




\begin{tabular}{l|l} 
No.188-20 & $\begin{array}{l}\text { Mantenimiento medidas distanciamiento social. Extensión toque de queda } \\
\text { hasta el 13 de junio de lunes a sábado de 7:00 p.m. a 5:00 a.m. y domingos de } \\
\text { 51/06/2020 } \\
\text { 5o.00 p.m. a 5:00 a.m. }\end{array}$ \\
\hline 12/06/2020 & $\begin{array}{l}\text { Prórroga el Estado de Emergencia por 17 días. Remisión Informes a } \\
\text { Comisión Bicameral. }\end{array}$ \\
\hline No.214-20 & $\begin{array}{l}\text { Mantenimiento medidas distanciamiento social. Extensión toque de queda } \\
\text { por 14 días hasta el sábado 27 de junio, de 8:00 p.m. a 5:00 a.m. } \\
\text { Permitir en horario de toque de queda la circulación de funcionarios de la } \\
\text { Junta Central Electoral y las juntas municipales que laboran en el montaje } \\
\text { de las elecciones. }\end{array}$ \\
\hline
\end{tabular}

Fuente: Consultoría Jurídica del Poder Ejecutivo. http://www.consultoria.gov.do/

\section{Participación del Poder Legislativo en la gestión y supervisión de la crisis}

Durante la emergencia, el Congreso Nacional -conformado por el Senado y la Cámara de Diputados- se reunió con la plenitud de sus atribuciones normativas y fiscalizadoras (art.266.2 Const.RD), aunque introdujo algunos cambios para evitar la propagación del Coronavirus. Se redujo el horario de trabajo (8:00am-14:00pm), fueron suspendidas las sesiones de los viernes, se aprobó un protocolo para reuniones virtuales, y se impuso el uso de guantes en las votaciones.

\subsection{El Congreso Nacional}

En cumplimiento del art. 22 de la Ley Reguladora de los Estados de Excepción, el Congreso nombró el 19 de marzo de 2020 la Comisión Bilateral de Seguimiento a la Actuaciones y Medidas adoptadas durante el Estado de Emergencia. Sus 23 miembros fueron los encargados de recibir los informes del Ejecutivo con el detalle de las decisiones adoptadas. Presidida por el senador peledeísta Luis Canánn, estaban presentes las principales fuerzas que integraron la alianza oficialista «Bloque Progresista» (15 PLD; 1 PLR), la alianza opositora «Convergencia por un Mejor País» (PRM 5; PRSC 1) y otras fuerzas independientes (1 PQDC). Con la cercanía de la cita con las urnas, la lucha entre facciones y la negociación entre posibles aliados mermaron el peso del oficialismo en la Comisión, ya que los 2 miembros leonelistas y el representante del PLR se retiraron de la alianza que apoyaba al PLD, aunque esto no endureció la beligerancia de sus funciones de supervisión.

La Comisión Bilateral se reunió en once ocasiones, cinco de ellas de forma telemática a través de la plataforma Zoom. El resto de las sesiones se celebraron en la Cámara de Diputados (3), en el Senado (1), y en dos ocasiones salieron del Hemiciclo para conocer las gestiones del Ministerio de Defensa y de Salud Pública. La asistencia fue muy irregular y ninguna de las reuniones contó con la presencia de sus 23 miembros. Como muestra la Tabla 2, la Comisión despertó poco interés, ya que cuatro de las reuniones no contaron con el quórum para celebrarse válidamente; en tres de ellas estuvieron presentes menos de la mitad de sus 
integrantes; y solo cuatro sesiones registraron una asistencia igual o superior al 70\%. La última reunión de la Comisión celebrada el 24 de junio, -diez días antes de las elecciones y con los diputados y senadores inmersos en la campaña- solo 3 legisladores se conectaron virtualmente para conocer el quinto y sexto Informe del Gobierno. En esta última sesión, la Comisión solicitó a la JCE y al Ministerio de Educación los protocolos sanitarios a seguir en las elecciones y en la vuelta al colegio, así como el Informe final al Ministro de la Presidencia, con las fases del desconfinamiento.

El Ejecutivo cumplió con el mandato constitucional de informar a la Comisión presentándole los informes quincenales y recibió las visitas de los responsables de los Ministerios con competencias en la gestión de la pandemia. Así, el 14 de abril, los Ministros coordinadores de la Comisión de Alto Nivel para el Control del Coronavirus y de las Comisiones de Asuntos Económicos y Sociales, acudieron a la Cámara de Diputados para presentar a los 16 legisladores asistentes, las medidas adoptadas en sus respectivos ámbitos. Para conocer las incidencias de la gestión hospitalaria, la Comisión recibió al Ministro de Salud Pública y al Director del Servicio Nacional de Salud el 5 de mayo, y a la representante de la Organización Panamericana de la Salud, el 26 del mismo mes. La Comisión realizó otras dos visitas institucionales. La primera de ellas al Centro de Ciberseguridad e Inteligencia, para conocer los desafíos de la organización de las elecciones generales del 5 de julio dado el especial contexto sanitario. Y la segunda, al Laboratorio Nacional de Salud Pública encargado de realizar las pruebas diagnósticas, ya que la Seguridad Social asumió el coste también para aquellos no afiliados al Seguro Familiar de Salud.

La Comisión Bicameral de Seguimiento a las Actuaciones y Medidas adoptadas durante el Estado de Emergencia, ejerció como mero órgano receptor de informaciones. El único papel proactivo fiscalizador consistió en solicitar la comparecencia del coordinador de la Comisión de Alto Nivel para que respondiera a las preguntas formuladas en una de las sesiones previas. Sin embargo, la respuesta del Ministro de la Presidencia no pareció despertar mucho interés entre sus miembros, ya que la audiencia del 19 de mayo se celebró sin el quórum mínimo requerido (7/23). Por tanto, un papel de representación más propio del protocolo institucional, que refleja su naturaleza de instancia ratificadora y legitimadora de la acción de gobierno (ALCÁNTARA, GARCÍA MONTERO Y SÁNCHEZ, 2005). 
Tabla 2 - Actividad Comisión Bicameral de Seguimiento a las Actuaciones y Medidas adoptadas durante el Estado de Emergencia (19/03/2020 al 30/06/2020).

\begin{tabular}{|c|c|c|c|c|}
\hline & Fecha & Objetivos reunion & Ubicación & Asistencia \\
\hline Marzo & $3 / 24 / 2020$ & $\begin{array}{l}\text { Conocer la Resolución que da } \\
\text { seguimiento a las actuaciones y medidas } \\
\text { tomadas durante el período el Estado de } \\
\text { Emergencia }\end{array}$ & $\begin{array}{l}\text { Cámara de } \\
\text { Diputados }\end{array}$ & $\begin{array}{c}7 / 23 \\
\text { sin quorum }\end{array}$ \\
\hline & $4 / 03 / 2020$ & $\begin{array}{l}\text { Conocer el primer Informe remitido } \\
\text { por el Poder Ejecutivo a las Cámaras } \\
\text { Legislativas. } \\
\text { Conocer el protocolo para las reuniones } \\
\text { virtuales de la Comisión a través de la } \\
\text { plataforma Zoom elaborado por los } \\
\text { equipos de apoyo de ambas Cámaras. }\end{array}$ & Senado & $17 / 23$ \\
\hline Abril & $4 / 14 / 2020$ & $\begin{array}{l}\text { Recibir al Ministro de la Presidencia y } \\
\text { coordinador de la Comisión de Alto } \\
\text { Nivel para la Prevención y Control } \\
\text { Coronavirus; al Ministro de Hacienda } \\
\text { y coordinador de la Comisión para } \\
\text { Atender Asuntos Económicos y de } \\
\text { Empleos; al Ministro Administrativo de } \\
\text { la Presidencia y coordinador para } \\
\text { atender los Asuntos Sociales, y al } \\
\text { Consultor Jurídico del Poder } \\
\text { Ejecutivo. }\end{array}$ & $\begin{array}{l}\text { Cámara de } \\
\text { Diputados }\end{array}$ & $16 / 23$ \\
\hline & $4 / 21 / 2020$ & $\begin{array}{l}\text { Conocer el segundo Informe remitido } \\
\text { por el Poder Ejecutivo a las Cámaras } \\
\text { Legislativa. }\end{array}$ & $\begin{array}{c}\text { Entorno } \\
\text { virtual }\end{array}$ & $18 / 23$ \\
\hline \multirow{3}{*}{ Mayo } & $5 / 05 / 2020$ & $\begin{array}{l}\text { Recibir al Ministro de Salud Pública y } \\
\text { Asistencia Social, y al director del } \\
\text { Servicio de Nacional de Salud } \\
\text { (SENASA). }\end{array}$ & Entorno virtual & $17 / 23$ \\
\hline & $5 / 07 / 2020$ & $\begin{array}{l}\text { Conocer el tercer Informe remitido del } \\
\text { Poder Ejecutivo a las Cámaras } \\
\text { Legislativas. }\end{array}$ & $\begin{array}{l}\text { Cámara de } \\
\text { Diputados }\end{array}$ & $10 / 23$ \\
\hline & $5 / 19 / 2020$ & $\begin{array}{l}\text { Conocer el cuarto Informe remitido } \\
\text { por el Poder Ejecutivo a las Cámaras } \\
\text { Legislativas. } \\
\text { Conocer las respuestas remitidas por el } \\
\text { coordinador de la Comisión de Alto } \\
\text { Nivel para la Prevención y Control del }\end{array}$ & $\begin{array}{c}\text { Entorno } \\
\text { virtual }\end{array}$ & $\begin{array}{c}7 / 23 \\
\text { sin quorum }\end{array}$ \\
\hline
\end{tabular}


Coronavirus, a las interrogantes planteadas por la Comisión Bicameral.

5/26/2020 Recibir a la representante de la Oficina Panamericana de la Salud (OPS).

Visitar el Centro de Control,

$5 / 27 / 2020$ Comunicaciones, Ciberseguridad e Inteligencia del Ministerio de Defensa.

Ministerio de Defensa $11 / 23$

Ministerio de Salud Pública $3 / 23$ $6 / 02 / 2020$ Visitar el Laboratorio Nacional de Salud Pública Dr. Defilló.

Presentar y conocer el quinto y sexto Junio $6 / 24 / 2020$
Entorno

virtual sin quorum los acontecimientos durante la vigencia del Estado de Emergencia.

Fuente: Sistema de Información Legislativa (SIL), Cámara de Diputados de la República Dominicana. https://www.diputadosrd.gob.do/sil/

\subsection{El papel de la Cámara de Diputados}

Durante la emergencia nacional el Pleno se reunió en diez ocasiones, cinco de ellas en sesión extraordinaria convocada por la presidencia del órgano Legislativo. El Pleno es la máxima autoridad de la Cámara y requiere de la presencia de más de la mitad de los diputados (96/190) para la validez de sus decisiones. De los 53 asuntos sometidos a votación, 15 de ellos (28\%) tuvieron por objeto fiscalizar la gestión de la crisis sanitaria utilizando distintos instrumentos del control político parlamentário:

- Control del procedimiento legislativo a través de la iniciativa normativa y la convalidación de decretos del Ejecutivo:

a) Autorizar la declaratoria del estado de emergencia y sus prórrogas (art. 93.1.e Const.RD): En el Pleno extraordinario del 19 de marzo (0004-2020-PLO), la Cámara aprobó la Resolución que autorizaba al Presidente declarar el Estado de Emergencia por un plazo máximo de 25 días. Los 146 asistentes votaron por unanimidad conceder al Gobierno facultades extraordinarias para combatir la crisis sanitaria. La Cámara aprobó también las cinco solicitudes de prórroga (00005-PLO; 00006-PLO; 00007PLO; 00008-PLO; 00009-PLO; 00010-PLO; y 00011-PLO), aunque no por el plazo pretendido de 25 días. La propuesta del opositor PRM de reducirla a 17 días, fue secundada por otras fuerzas minoritarias opositoras como el PRSC, el PQDC, e incluso 
por la facción oficialista liderada por el exmandatario Leonel Fernández enfrentada al danilismo. Entre otras razones, los partidos alegaron que el toque de queda y la prohibición de aglomeraciones mermaba el proselitismo de los contendientes durante la campaña electoral. La oposición acusó al Ejecutivo de alargar la limitación de derechos y libertades para invisibilizar a la competencia y rentabilizar el protagonismo del Gobierno en la respuesta pública frente a la pandemia (BENITO, 2020).

b) Legislar acerca de toda materia que no sea competencia de otro Poder del Estado (art. 93.1.q. Const.RD): En el Pleno del 28 de abril (0006-PLO), el diputado Pedro Botello del Reformista Social Cristiano (PRSC) somete a consideración un Proyecto de Ley para permitir el retiro anticipado del $30 \%$ de los fondos acumulados por los trabajadores en las Administradoras de Fondos de Pensiones (AFP). Comienza así la tramitación de esta polémica iniciativa, enviada primero a la Comisión Permanente de Hacienda (0009-PLO) y aprobada por la Cámara en segunda lectura (0012-PLO; 0013PLO). La propuesta no contaba con el beneplácito del Gobernandor del Banco Central -reconfirmado por la nueva administración de Abinader- por sus posibles efectos inflacionistas y alteración de la tasa de cambio. El Banco Interamericano de Desarrollo (BID) también se pronunció al respecto, considerándola una medida inviable para las pensiones básicas y que de permitirse, debería ser un préstamo y no un anticipo que no superase el $10 \%$ de los fondos. La iniciativa del diputado Botello, tachada de electoralista por sus adversarios, ha contado con gran apoyo popular y mediático, rentabilizando el descontento ciudadano con las enormes ganancias de las AFP del país. Solo en 2019, la rentabilidad nominal sobre el capital de estas administradoras fue del $51 \%$, mientras que la de los protegidos del sistema fue de un escaso 5,47\% (SIPEN, 2019).

La propuesta dominicana es similar a la aprobada el 23 de julio por el Legislativo Chileno, que permite el retiro del $10 \%$ de los fondos previsionales hasta un máximo de USD\$5,000 y que el Estado devolvería al momento de la jubilación. Esta Ley tampoco cuenta con el favor del Ejecutivo de Piñera, que la considera una medida populista que compromete el futuro de las jubilaciones e impide la reforma estructural del sistema de pensiones. De igual manera, Costa Rica aprobó en abril el Proyecto de Ley de Retiro Anticipado del Fondo de Capitalización Laboral para aquellos trabajadores que perdieron su empleo a causa de la Covid19. En México, su legislación laboral ya permitía el retiro de hasta el $10 \%$ de los fondos previsionales una vez cada 5 años, cuando el trabajador se quedase sin empleo por más de 45 días. Con el cese de la actividad productiva, el uso de esta herramienta por parte de los trabajadores mexicanos ha registrado máximos históricos, superando en junio de 2020 los USD \$83 millones. También el Legislativo Peruano aprobó en abril el retiro de hasta USD \$570 dólares para beneficiar a cerca de 1,4 millones de cotizantes peruanos que por sus bajas 
aportaciones al sistema no tendrían jubilación. El Congreso Peruano estudia además una propuesta de retiro del 25\% para todos los cotizantes de las Administradoras de Fondos de Pensiones, que tampoco cuenta con el apoyo del Gobierno de Vizcarra. Otros países como Colombia y Brasil estarían considerando la posibilidad de autorizar retiros similares. Estas propuestas evidencian que la incertidumbre y volatilidad de la producción afectan también a las rentas medias, principales sufragantes de los sistemas de capitalización individual. Un escenario que amerita la reconsideración de lo público y exige afrontar cambios estructurales en los regímenes de bienestar latinoamericanos de base neoliberal. Mientras que algunas democracias europeas han optado por la colectivización de los riesgos para garantizar la cohesión social -con medidas como la renta básica universal-, en las iniciativas latinoamericanas reseñadas, los individuos asumen el riesgo en perjuicio de sus pensiones.

\section{- Interpelaciones al Gobierno:}

Citar a los miembros del Gabinete y de los organismos del Estado ante las Comisiones del Congreso para edificarlas sobre los actos de su administración (art. 93.2.c Const.RD) y supervisar todas las políticas públicas que implemente el Ejecutivo (93.2.f.Const.RD): Durante la tramitación parlamentaria de la prórroga solicitada en mayo, el bloque opositor sometió a consideración del Pleno un Proyecto de Resolución Bicameral pidiendo al Ejecutivo medidas adicionales frente a la pandemia (0007-2020-PLO). La iniciativa fue cursada por los portavoces de los partidos de la oposición que conformaron la alianza «Convergencia por un Mejor País» -PRM y PRSC- y por el portavoz del PQDC. Los reclamantes solicitaron al Gobierno incrementar las pruebas diagnósticas en cinco mil diarias, enviar a la Comisión Bicameral los informes y respetar los procedimientos en las licitaciones. Este requerimiento sobre la transparencia y legalidad de las compras durante el Estado de Emergencia llega a la Cámara tras el ya mencionado escándalo en la adquisición de alimentos del INAIPI. El 26 de febrero 20 días antes del Estado de Emergencia- el Gobierno promulgó el Decreto 87-20 sobre emergencia en las compras y contrataciones para prevenir y responder al Coronavirus, estableciendo un periodo especial de 120 días en el que se flexibilizaron los controles. Como denunciaron algunas organizaciones (VANCE CENTER, 2020), el Estado de Emergencia en el país fue escenario de oportunidad para los sobrecostes y la opacidad. 


\section{- $\quad$ Control presupuestario:}

Votar el Presupuesto de Ingresos y Ley de Gastos Públicos, aprobar modificaciones y gastos extraordinarios para los cuales el Ejecutivo solicite crédito (art. 93.1.i.Const.RD): La Cámara recibe el 15 de junio el Proyecto de Ley del Ejecutivo para modificar el Presupuesto General del Estado para el año 2020. El Gobierno daba así cumplimiento al mandato constitucional (art.234) que prohíbe trasladar recursos entre instituciones sin que medie ley que lo autorice; y a la Ley Orgánica de Presupuesto para el Sector Público, que requiere someter al Congreso las modificaciones y adiciones de financiamiento (art.48). En abril, el Ejecutivo recibió 650\$USD millones del Instrumento de Financiamiento Rápido del Fondo Monetario Internacional (FMI) y propone que estos fondos -destinados a paliar necesidades urgentes de la balanza de pagos- sean utilizados para sufragar los gastos de salud de la Covid-19. El Gobierno estimó en un 19,5\% el incremento de los gastos para el resto del año 2020, así como una disminución de ingresos del 10,3\%. Además de disponer de los fondos procedentes de algunos Ministerios -Hacienda, Defensa, Interior y Policía, Agricultura y Turismo entre otros, el Estado Dominicano aumentó el financiamiento externo y doméstico en un 46\% y 14,29\% respectivamente para sufragar los gastos sobrevenidos por el Coronavirus. El Ministerio de la Presidencia (29\%), la JCE (27\%) y el Ministerio de Salud Pública (21\%) fueron los principales receptores de los nuevos fondos. El Proyecto de Ley, previamente aprobado en el Senado, siguió el trámite parlamentario de consideración (00012-PLO) y segunda lectura (00013-PLO), y fue aprobado por los 96 representantes que asistieron al Pleno de la Cámara, salvando así el requisito de quórum mínimo.

En los 21 considerandos que preceden a la Ley No.68-20 que modifica el Presupuesto General, el Ejecutivo expone las razones que justifican los nuevos techos de gastos y la reasignación de recursos entre capítulos para preservar la estabilidad macroeconómica. Con respecto al aumento de gastos, el desbordamiento de la demanda evidenció el déficit en infraestructuras y en cobertura de salud, ya que la Seguridad Social solo protege al 52,5\% de los dominicanos. A pesar de que la Estrategia Nacional de Desarrollo 2030 ordena que el presupuesto sanitario supere el 3\% del PIB, Dominicana sigue siendo uno de los países de América Latina con menor gasto en salud por habitante. En 2019, el Gobierno destinó el 1,8\% del PIB, mientras que el gasto de bolsillo en salud de los hogares dominicanos representó el 2,7\% del PIB (ADESA, 2019). Además de estos gastos extraordinarios ocasionados por el Coronavirus, el Ejecutivo incluyó en el considerando décimo del Proyecto de Ley otros de naturaleza política y electoral ajenos a la pandemia. El fallo técnico en el voto electrónico provocó la suspensión de las elecciones municipales de febrero y la JCE requirió de presupuesto adicional para organizar una nueva contienda el 15 de marzo, cuatro días antes de la declaración 
de emergencia. Este gasto también afectó a las cuentas de los partidos, que pidieron apoyo presupuestario para financiar la campaña de las generales del 5 de julio de 2020. El peso del financiamiento de los partidos y de la maquinaria electoral, que supera al recibido por el Ministerio de Sanidad para enfrentar la pandemia, da cuenta de la dimensión de la carterización del sistema señalada por la literatura (BENITO, 2015, p.100; JIMÉNEZ POLANCO, 2016). Con respecto a la disminución de la recaudación, el Gobierno atribuye al impago de los usuarios el déficit de las distribuidoras eléctricas Edesur, Edenorte y Edeeste, que recibieron la orden de no cortar el suministro durante la emergencia. Esta deuda se sumaría a la contraída por el Estado por valor de USD $\$ 1,750,9$ millones y que tiene como propósito reconvertir el ineficiente y subsidiado sector eléctrico nacional incorporando la generadora estatal Punta Catalina, la controvertida obra de la administración Medina.

Como sucediera en las sesiones de la Comisión Bilateral, la asistencia a los diez Plenos celebrados en la Cámara de Diputados durante la emergencia fue muy irregular. Ninguna de las reuniones contó con la presencia de los 190 diputados y dos de ellas fueron levantadas por falta de quórum. A finales de mayo, con la intensificación de la campaña electoral, disminuye considerablemente el interés de los representantes y los Plenos se celebran con menos de la mitad del aforo. Como muestra la Tabla 3, de los 53 asuntos sometidos a votación durante el Estado de Emergencia, 18 fueron conocidos por Plenos cuyo aforo rondaba el 65\%, y otras 19 iniciativas fueron debatidas con menos de la mitad de los representantes del Hemiciclo. Tampoco hubo mucho tiempo para el debate, ya que la duración media de las sesiones fue de una hora y media, salvo aquellas en las que se discutió la modificación del Presupuesto (00012PLO) y la cuarta prórroga (00009-PLO), que se prolongaron por más de tres horas.

La supervisión de la gestión de la pandemia representó el 28\% de la actividad plenaria de la Cámara de Diputados durante el Estado de Emergencia. La Cámara continuó cumpliendo con sus responsabilidades normativas y fiscalizadoras y el resto de los 38 asuntos tratados tuvieron como propósito (Ver detalle en Anexo): promulgar y modificar legislación vigente (16,9\%); aprobar acuerdos internacionales concertados por el Gobierno (15\%); gestionar cambios de titularidad en la representación $(9,4 \%)$; aprobar contratos de venta de propiedades públicas a particulares (15\%); y fiscalizar la gestión económica y los actos del Poder Ejecutivo $(15 \%)$.

El relato de la actividad plenaria de la Cámara de Diputados durante el primer Estado de Emergencia revela algunos de los rasgos del quehacer legislativo en el país, como la débil cohesión legislativa y el individualismo en el trabajo parlamentario (BENITO, 2017, p.166). La única propuesta normativa para enfrentar la pandemia no surgió de la bancada oficialista u opositora en la que el partido hablase como una sola voz colectiva, sino de la iniciativa de un representante. Como ha demostrado la literatura, el voto preferencial y el tamaño de las circunscripciones (CAREY, 2009; MUÑOZ, 2011), favorece el trabajo en solitario de los 
diputados dominicanos y disminuye el valor informativo de las posturas de los partidos. En la interpelación al Gobierno, solo hubo una única actuación en bloque de la oposición para solicitar, a través de una Resolución Bicameral, medidas adicionales. De nuevo, la naturaleza ratificadora y la ausencia de debate entre los grupos parlamentarios para orientar las políticas marcaron la actividad normativa, y la Ley de Presupuesto se aprobó sin que se discutiera enmienda alguna.

Tabla 3 - . Sesiones del Pleno de la Cámara de Diputados celebradas bajo el Estado de Emergencia (19/03/2020 al 30/06/2020)

\begin{tabular}{|c|c|c|c|c|c|c|c|}
\hline \multicolumn{2}{|c|}{ Fecha } & Sesión & \multicolumn{3}{|c|}{ Votaciones } & Duración & Estado \\
\hline \multirow{6}{*}{$\begin{array}{l}\text { Marz } \\
\text { o }\end{array}$} & \multirow{6}{*}{$\begin{array}{l}3 / 19 / 20 \\
20\end{array}$} & \multirow{6}{*}{$\begin{array}{l}\text { 00004- } \\
\text { 2020-PLO } \\
\text { Extraordina } \\
\text { ria }\end{array}$} & $\mathrm{T}(142 / 190)$ & $\begin{array}{c}\mathrm{Si} \\
(141)\end{array}$ & No (1) & \multirow{6}{*}{$\begin{array}{l}02: 58 \mathrm{pm} \\
03: 30 \mathrm{pm}\end{array}$} & \multirow{6}{*}{$\begin{array}{l}\text { Levantada } \\
\text { por la } \\
\text { presidencia }\end{array}$} \\
\hline & & & $T(146 / 190) *$ & $\begin{array}{c}S i \\
(146) *\end{array}$ & $\begin{array}{l}\text { No } \\
(0) *\end{array}$ & & \\
\hline & & & $\mathrm{T}(142 / 190)$ & $\begin{array}{c}\mathrm{Si} \\
(142)\end{array}$ & No $(0)$ & & \\
\hline & & & $\mathrm{T}(132 / 190)$ & $\begin{array}{c}\mathrm{Si} \\
(132)\end{array}$ & No $(0)$ & & \\
\hline & & & $\mathrm{T}(126 / 190)$ & $\begin{array}{c}\mathrm{Si} \\
(126)\end{array}$ & No $(0)$ & & \\
\hline & & & $\mathrm{T}(127 / 190)$ & $\begin{array}{c}\mathrm{Si} \\
(127)\end{array}$ & No $(0)$ & & \\
\hline \multirow{2}{*}{ Abril } & $\begin{array}{l}4 / 09 / 20 \\
20\end{array}$ & $\begin{array}{c}\text { 00005- } \\
\text { 2020-PLO } \\
\text { Ordinaria }\end{array}$ & $T(138 / 190) *$ & \multicolumn{2}{|c|}{$\begin{array}{l}\text { Aprobación } \\
\text { conjunta a mano } \\
\text { alzada* }\end{array}$} & $\begin{array}{l}11: 28 \mathrm{am} \\
12: 59 \mathrm{pm}\end{array}$ & $\begin{array}{l}\text { Concluido } \\
\text { orden del } \\
\text { día }\end{array}$ \\
\hline & $\begin{array}{l}4 / 28 / 20 \\
20\end{array}$ & $\begin{array}{c}\text { 00006- } \\
\text { 2020-PLO } \\
\text { Ordinaria }\end{array}$ & $T(156 / 190) *$ & \multicolumn{2}{|c|}{$\begin{array}{l}\text { Aprobación } \\
\text { conjunta a mano } \\
\text { alzada* }\end{array}$} & $\begin{array}{l}12: 52 \mathrm{pm} \\
02: 32 \mathrm{pm}\end{array}$ & $\begin{array}{l}\text { Concluido } \\
\text { orden del } \\
\text { día }\end{array}$ \\
\hline \multirow{12}{*}{ Mayo } & $\begin{array}{l}5 / 14 / 20 \\
20\end{array}$ & $\begin{array}{c}\text { 00007- } \\
\text { 2020-PLO } \\
\text { Ordinaria }\end{array}$ & $T(173 / 190)^{*}$ & $\begin{array}{l}\text { Aproba } \\
\text { mano al }\end{array}$ & $\begin{array}{l}\text { ón a } \\
\text { ada* }\end{array}$ & $\begin{array}{l}02: 58 \mathrm{pm} \\
04: 33 \mathrm{pm}\end{array}$ & $\begin{array}{l}\text { Concluido } \\
\text { orden del } \\
\text { día }\end{array}$ \\
\hline & $\begin{array}{l}5 / 29 / 20 \\
20\end{array}$ & $\begin{array}{c}\text { 00008- } \\
\text { 2020-PLO } \\
\text { Extraordina } \\
\text { ria }\end{array}$ & $T(89 / 190)^{*}$ & $\begin{array}{c}S i \\
(89)^{*}\end{array}$ & $\begin{array}{l}N o \\
(0)^{*}\end{array}$ & $\begin{array}{l}12: 53 \mathrm{pm} \\
01: 12 \mathrm{pm}\end{array}$ & $\begin{array}{l}\text { Levantada } \\
\text { por falta } \\
\text { quórum } \\
\text { votación }\end{array}$ \\
\hline & \multirow{10}{*}{$\begin{array}{l}5 / 30 / 20 \\
20\end{array}$} & \multirow{10}{*}{$\begin{array}{l}\text { 00009- } \\
\text { 2020-PLO } \\
\text { Extraordina } \\
\text { ria }\end{array}$} & $\mathrm{T}(143 / 190)$ & $\begin{array}{c}\mathrm{Si} \\
(126)\end{array}$ & $\begin{array}{l}\text { No } \\
\text { (17) }\end{array}$ & \multirow{10}{*}{$\begin{array}{l}12: 22 \mathrm{pm} \\
04: 02 \mathrm{pm}\end{array}$} & \multirow{10}{*}{$\begin{array}{l}\text { Levantada } \\
\text { por la } \\
\text { presidencia }\end{array}$} \\
\hline & & & $T(140 / 190) *$ & $\begin{array}{c}S i \\
(124) *\end{array}$ & $\begin{array}{c}N o \\
(16) *\end{array}$ & & \\
\hline & & & $\mathrm{T}(96 / 190)$ & $\mathrm{Si}(95)$ & No (1) & & \\
\hline & & & $\mathrm{T}(97 / 190)$ & $\mathrm{Si}(97)$ & No $(0)$ & & \\
\hline & & & $\mathrm{T}(95 / 190)$ & $\mathrm{Si}(95)$ & No $(0)$ & & \\
\hline & & & $\mathrm{T}(96 / 190)$ & Si (96) & No $(0)$ & & \\
\hline & & & $\mathrm{T}(96 / 190)$ & Si (96) & No $(0)$ & & \\
\hline & & & $\mathrm{T}(97 / 190)$ & $\mathrm{Si}(95)$ & No (2) & & \\
\hline & & & $\mathrm{T}(94 / 190)$ & Si (94) & No $(0)$ & & \\
\hline & & & $\mathrm{T}(95 / 190)$ & $\mathrm{Si}(95)$ & No $(0)$ & & \\
\hline
\end{tabular}




\begin{tabular}{|c|c|c|c|c|c|c|c|}
\hline & & & $T(150 / 190) *$ & $\begin{array}{c}S i \\
(149)^{*}\end{array}$ & $\begin{array}{l}\text { No } \\
(1)^{*}\end{array}$ & & \\
\hline \multirow{32}{*}{ Junio } & \multirow{3}{*}{$\begin{array}{l}6 / 10 / 20 \\
20\end{array}$} & \multirow{3}{*}{$\begin{array}{c}\text { 00010- } \\
\text { 2020-PLO } \\
\text { Ordinaria }\end{array}$} & $T(94 / 190) *$ & $\begin{array}{c}S i \\
(89) *\end{array}$ & $\begin{array}{l}N o \\
(5)^{*}\end{array}$ & \multirow{3}{*}{$\begin{array}{l}12: 30 \mathrm{pm} \\
12: 45 \mathrm{pm}\end{array}$} & \multirow{3}{*}{$\begin{array}{l}\text { Levantada } \\
\text { por falta } \\
\text { quórum } \\
\text { votación }\end{array}$} \\
\hline & & & $\mathrm{T}(93 / 190)$ & $\mathrm{Si}(91)$ & No (2) & & \\
\hline & & & $\mathrm{T}(93 / 190)$ & $\mathrm{Si}(91)$ & No (2) & & \\
\hline & \multirow{11}{*}{$\begin{array}{l}6 / 12 / 20 \\
20\end{array}$} & \multirow{11}{*}{$\begin{array}{c}\text { 00011- } \\
\text { 2020-PLO } \\
\text { Extraordina } \\
\text { ria }\end{array}$} & $T(97 / 190) *$ & $\begin{array}{c}S i \\
(94)^{*}\end{array}$ & $\begin{array}{l}N o \\
(3) *\end{array}$ & \multirow{11}{*}{$\begin{array}{l}12: 20 \mathrm{pm} \\
01: 38 \mathrm{pm}\end{array}$} & \multirow{11}{*}{$\begin{array}{l}\text { Concluido } \\
\text { orden del } \\
\text { día }\end{array}$} \\
\hline & & & $\mathrm{T}(100 / 190)$ & $\mathrm{Si}(95)$ & No (5) & & \\
\hline & & & $\mathrm{T}(95 / 190)$ & $\mathrm{Si}(94)$ & No (1) & & \\
\hline & & & $\mathrm{T}(141 / 190)$ & $\begin{array}{c}\mathrm{Si} \\
(140)\end{array}$ & No (1) & & \\
\hline & & & $\mathrm{T}(156 / 190)$ & $\begin{array}{c}\mathrm{Si} \\
(156)\end{array}$ & No $(0)$ & & \\
\hline & & & $\begin{array}{c}\mathrm{T} \\
(95 / 19300)\end{array}$ & $\mathrm{Si}(95)$ & No $(0)$ & & \\
\hline & & & $\mathrm{T}(95 / 190)$ & $\mathrm{Si}(95)$ & No $(0)$ & & \\
\hline & & & $\mathrm{T}(95 / 190)$ & $\mathrm{Si}(95)$ & No $(0)$ & & \\
\hline & & & $\mathrm{T}(100 / 190)$ & $\mathrm{Si}(93)$ & No (7) & & \\
\hline & & & $\mathrm{T}(93 / 190)$ & $\mathrm{Si}(86)$ & No (7) & & \\
\hline & & & $\mathrm{T}(95 / 190)$ & $\mathrm{Si}(90)$ & No (5) & & \\
\hline & \multirow{9}{*}{$\begin{array}{l}6 / 18 / 20 \\
20\end{array}$} & \multirow{9}{*}{$\begin{array}{l}\text { 00012- } \\
\text { 2020-PLO } \\
\text { Ordinaria }\end{array}$} & $T(96 / 190) *$ & $\begin{array}{c}S i \\
(96)^{*}\end{array}$ & $\begin{array}{l}\text { No } \\
(0)^{*}\end{array}$ & \multirow{9}{*}{$\begin{array}{l}12: 46 \mathrm{pm} \\
04: 05 \mathrm{pm}\end{array}$} & \multirow{9}{*}{$\begin{array}{l}\text { Levantada } \\
\text { por la } \\
\text { presidencia }\end{array}$} \\
\hline & & & $T(96 / 190) *$ & $\begin{array}{c}S i \\
(96)^{*}\end{array}$ & $\begin{array}{l}\text { No } \\
(0) *\end{array}$ & & \\
\hline & & & $\mathrm{T}(95 / 190)$ & $\mathrm{Si}(95)$ & No $(0)$ & & \\
\hline & & & $\mathrm{T}(3 / 190)$ & Si (3) & No $(0)$ & & \\
\hline & & & $\mathrm{T}(125 / 190)$ & $\mathrm{Si}(30)$ & $\begin{array}{l}\text { No } \\
(95)\end{array}$ & & \\
\hline & & & $\mathrm{T}(123 / 190)$ & $\mathrm{Si}(95)$ & $\begin{array}{l}\text { No } \\
(28)\end{array}$ & & \\
\hline & & & $\mathrm{T}(96 / 190)$ & $\mathrm{Si}(96)$ & No $(0)$ & & \\
\hline & & & $\mathrm{T}(96 / 190)$ & $\mathrm{Si}(96)$ & No $(0)$ & & \\
\hline & & & $\mathrm{T}(96 / 190)$ & $\mathrm{Si}(96)$ & No $(0)$ & & \\
\hline & \multirow{9}{*}{$\begin{array}{l}6 / 22 / 20 \\
20\end{array}$} & \multirow{9}{*}{$\begin{array}{c}\text { 00013- } \\
\text { 2020-PLO } \\
\text { Extraordina } \\
\text { ria }\end{array}$} & $T(96 / 190)^{*}$ & $\begin{array}{c}S i \\
(96) *\end{array}$ & $\begin{array}{l}N o \\
(0) *\end{array}$ & \multirow{9}{*}{$\begin{array}{l}01: 00 \mathrm{pm} \\
01: 43 \mathrm{pm}\end{array}$} & \multirow{9}{*}{$\begin{array}{l}\text { Concluido } \\
\text { orden del } \\
\text { día }\end{array}$} \\
\hline & & & $T(96 / 190) *$ & $\begin{array}{c}S i \\
(96)^{*}\end{array}$ & $\begin{array}{l}\text { No } \\
(0)^{*}\end{array}$ & & \\
\hline & & & $\mathrm{T}(139 / 190)$ & $\begin{array}{c}\mathrm{Si} \\
(125)\end{array}$ & $\begin{array}{l}\text { No } \\
(14)\end{array}$ & & \\
\hline & & & $\mathrm{T}(114 / 190)$ & $\begin{array}{c}\mathrm{Si} \\
(107)\end{array}$ & No (7) & & \\
\hline & & & $\mathrm{T}(52 / 190)$ & $\mathrm{Si}(51)$ & No (1) & & \\
\hline & & & $\mathrm{T}(95 / 190)$ & $\mathrm{Si}(60)$ & $\begin{array}{l}\text { No } \\
(35)\end{array}$ & & \\
\hline & & & $\mathrm{T}(95 / 190)$ & $\mathrm{Si}(65)$ & $\begin{array}{l}\text { No } \\
(30)\end{array}$ & & \\
\hline & & & $\mathrm{T}(94 / 190)$ & $\mathrm{Si}(73)$ & $\begin{array}{l}\text { No } \\
(21)\end{array}$ & & \\
\hline & & & $\mathrm{T}(98 / 190)$ & Si (98) & No $(0)$ & & \\
\hline
\end{tabular}

* Asunto Covid-19.

Fuente: Sistema de Información Legislativa (SIL), Cámara de Diputados de la República Dominicana. https://www.diputadosrd.gob.do/sil/ 


\subsection{El papel del Senado}

Durante el Estado de Emergencia el Senado de la República se reunió en doce ocasiones. El Pleno es la máxima autoridad de la Cámara Alta y requiere de la presencia de más de la mitad de los senadores (17/32) para la validez de sus decisiones. De los 108 asuntos sometidos a consideración, 32 de ellos $(29,6 \%)$ tuvieron por objeto fiscalizar la gestión de la crisis sanitaria utilizando los siguientes instrumentos del control:

- Control del procedimiento legislativo a través de la iniciativa normativa y la convalidación de decretos del Ejecutivo:

a) Autorizar la declaratoria del estado de emergencia y sus prórrogas (art. 93.1.e.Const.RD): El 18 de marzo (00180-PLO) Danilo Medina solicita la declaratoria de excepción. Tras ser aprobada por los 25 senadores asistentes, acude al día siguiente a la Cámara Baja para contar con su autorización. El Senado conoció y autorizó las prórrogas establecidas por decreto presidencial en las siguientes ocho sesiones plenarias (00181-PLO a 00188-PLO).

b) Legislar acerca de toda materia que no sea competencia de otro Poder del Estado (art.93.1.q. Const.RD): Dos senadores de la facción leonelista enfrentada al oficialismo presentaron en abril (00181-PLO) una modificación a la Ley de Seguridad Social para que los trabajadores accedieran al $20 \%$ de su fondo de pensión en estados de emergencia. Sin la repercusión mediática que su homóloga en la Cámara de Diputados, ambas propuestas fueron enviadas a la Comisión correspondiente para su fusión, tras el rechazo del Senado de incluirlas en la agenda del día. En esta misma sesión, se envió a estudio la propuesta de modificar los artículos 20 y 32 de la Ley que regula los Estados de Excepción, relativos al plazo del Congreso para conocer la declaratoria solicitada por el Ejecutivo, y las sanciones a los funcionarios que incumplan las órdenes de las autoridades.

\section{- Interpelaciones al Gobierno:}

Supervisar todas las políticas públicas que implemente el Ejecutivo (93.2.f.Const.RD): El Gobierno remitió al Senado el 6 de abril el primero de los seis informes preceptivos sobre las medidas adoptadas durante la pandemia. Y así lo hará con el segundo (00183PLO), cuarto (00187-PLO), quinto (00188-PLO) y sexto informe (00192-PLO), para conocimiento y aprobación del Senado. Además, fueron sometidas a la consideración del Pleno (00183-PLO y 00186-PLO) las siguientes propuestas de Resolución 
unilateral no vinculantes: reconocimiento del personal sanitario y de seguridad; proponer ante la ONU un fondo para vacunas y medicamentos; crear un fondo para padres de alumnos de colegios privados que hayan perdido su empleo a causa de la Covid-19; incluir al Seguro Nacional de Salud entre las instituciones que pueden licitar en estados de emergencia; y pedir al Gobierno medidas adicionales para combatir la pandemia, esta última a iniciativa del opositor PRM y de la facción leonelista del PLD. Solo la Resolución que solicitaba al Presidente proponer ante la ONU un fondo para desarrollar vacunas fue aprobada. Esta resolución fue además la única iniciativa conjunta de 14 senadores de las 6 fuerzas representadas, el resto fueron sometidas a título individual sin el endoso de la bancada partidista ${ }^{4}$.

\section{- Control presupuestario:}

Votar el Presupuesto de Ingresos y Ley de Gastos Públicos, aprobar modificaciones y gastos extraordinarios para los cuales el Ejecutivo solicite crédito (art. 93.1.i.Const.RD): El 13 de junio se celebraron 3 Plenos extraordinarios en los que el Gobierno presentó el Proyecto de Ley para modificar el Presupuesto General del Estado, adaptándolo a las circunstancias fiscales y económicas derivadas de la pandemia. La primera sesión (00191-PLO) fue levantada por falta de quórum en la votación, pero en las dos siguientes sería aprobado en primera (00192-PLO) y segunda lectura (00193-PLO). Dos días después pasaba a la Cámara para votación y aprobación final.

A diferencia de la Cámara de Diputados, la asistencia en el Senado se mantuvo por encima del $75 \%$ y los debates superaron las dos horas y media. A pesar de ello, el Gobierno no encontró resistencia a su ejecutoria, ya que el PLD controlaba el $81 \%$ de los escaños. Los asuntos de la pandemia representaron el 29,6\% de la actividad plenaria del Senado durante el Estado de Emergencia. La Cámara Alta continuó cumpliendo con sus responsabilidades y el resto de los 76 asuntos tratados tuvieron como propósito (Ver detalle en Anexo): promulgar y modificar legislación vigente (50\%); conocer el veto/observaciones del Ejecutivo a las Leyes (2,7\%); aprobar acuerdos internacionales concertados por el Gobierno (6,4\%); gestionar cambios de titularidad en la representación $(0,9 \%)$; conceder pensiones públicas a particulares $(0,9)$; ratificar nombramientos de personal diplomático (3,7\%); y fiscalizar los actos del Poder Ejecutivo y su gestión económica (5,5\%).

\footnotetext{
${ }^{4}$ Iniciativa 01345 de 14 senadores de todas las fuerzas políticas; Iniciativa 01342 de 1 senador del PRM; Iniciativa 01346 de 2 senadores del PLR y PLD; Iniciativa 01348 de 3 senadores del PLD
} 
De nuevo el individualismo y el carácter testimonial no vinculante de las iniciativas normativas, caracteriza la actividad propositiva del Senado para enfrentar la crisis sanitaria. Un papel escasamente participativo y reactivo en la toma de decisión política ya destacado por la literatura (GARCÍA MONTERO, 2007), que se constata también en situaciones de emergencia nacional.

Tabla 4 - Sesiones del Pleno del Senado de la República celebradas bajo el Estado de Emergencia (19/03/2020 al 30/06/2020)

\begin{tabular}{|c|c|c|c|c|c|}
\hline \multicolumn{2}{|c|}{ Fecha } & Sesión Pleno & Asistencia & Duración & Estado \\
\hline $\begin{array}{l}\text { Marz } \\
\mathrm{o}\end{array}$ & $\begin{array}{l}3 / 18 / 20 \\
20\end{array}$ & $\begin{array}{c}00180-\text { PLO } \\
\text { Ordinaria }\end{array}$ & $\mathrm{T}(25 / 32)^{*}$ & $\begin{array}{l}\text { 04:00pm } \\
04: 35 \mathrm{pm}\end{array}$ & $\begin{array}{l}\text { Concluido orden del } \\
\text { día }\end{array}$ \\
\hline \multirow{4}{*}{ Abril } & $\begin{array}{l}4 / 06 / 20 \\
20\end{array}$ & $\begin{array}{c}00181-\mathrm{PLO} \\
\text { Ordinaria }\end{array}$ & $\mathrm{T}(24 / 32)^{*}$ & $\begin{array}{l}\text { 11:06am } \\
\text { 02:40pm }\end{array}$ & $\begin{array}{l}\text { Concluido orden del } \\
\text { día }\end{array}$ \\
\hline & $\begin{array}{l}4 / 11 / 20 \\
20\end{array}$ & $\begin{array}{l}\text { 00182-PLO } \\
\text { Extraordinaria }\end{array}$ & $\mathrm{T}(24 / 32)^{*}$ & $\begin{array}{l}11: 06 \mathrm{am} \\
12: 40 \mathrm{pm}\end{array}$ & $\begin{array}{l}\text { Concluido orden del } \\
\text { día }\end{array}$ \\
\hline & $\begin{array}{l}4 / 26 / 20 \\
20\end{array}$ & $\begin{array}{c}00183-\mathrm{PLO} \\
\text { Ordinaria }\end{array}$ & $\mathrm{T}(29 / 32)^{*}$ & $\begin{array}{l}\text { 11:08am } \\
03: 45 \mathrm{pm}\end{array}$ & $\begin{array}{l}\text { Concluido orden del } \\
\text { día }\end{array}$ \\
\hline & $\begin{array}{l}4 / 29 / 20 \\
20\end{array}$ & $\begin{array}{l}\text { 00184-PLO } \\
\text { Extraordinaria }\end{array}$ & $\mathrm{T}(26 / 32)^{*}$ & $\begin{array}{l}11: 08 \mathrm{am} \\
12: 54 \mathrm{pm}\end{array}$ & $\begin{array}{l}\text { Concluido orden del } \\
\text { día }\end{array}$ \\
\hline \multirow{3}{*}{ Mayo } & $\begin{array}{l}5 / 13 / 20 \\
20\end{array}$ & $\begin{array}{l}00185-\mathrm{PLO} \\
\text { Extraordinaria }\end{array}$ & $\mathrm{T}(29 / 32)^{*}$ & $\begin{array}{l}\text { 11:08am } \\
03: 11 \mathrm{pm}\end{array}$ & $\begin{array}{l}\text { Concluido orden del } \\
\text { día }\end{array}$ \\
\hline & $\begin{array}{l}5 / 15 / 20 \\
20\end{array}$ & $\begin{array}{l}\text { 00186 -PLO } \\
\text { Extraordinaria }\end{array}$ & $\mathrm{T}(26 / 32)^{*}$ & $\begin{array}{l}10: 08 \mathrm{am} \\
12: 35 \mathrm{pm}\end{array}$ & $\begin{array}{l}\text { Concluido orden del } \\
\text { día }\end{array}$ \\
\hline & $\begin{array}{l}5 / 28 / 20 \\
20\end{array}$ & $\begin{array}{l}00187 \text {-PLO } \\
\text { Extraordinaria }\end{array}$ & $\mathrm{T}(25 / 32)^{*}$ & $\begin{array}{l}\text { 11:11am } \\
02: 20 \mathrm{pm}\end{array}$ & $\begin{array}{l}\text { Concluido orden del } \\
\text { día }\end{array}$ \\
\hline \multirow{4}{*}{ Junio } & $\begin{array}{l}6 / 01 / 20 \\
20\end{array}$ & $\begin{array}{l}00188-\mathrm{PLO} \\
\text { Extraordinaria }\end{array}$ & $\mathrm{T}(25 / 32)^{*}$ & $\begin{array}{l}\text { 10:07am } \\
11: 35 \mathrm{am}\end{array}$ & $\begin{array}{l}\text { Concluido orden del } \\
\text { día }\end{array}$ \\
\hline & $\begin{array}{l}6 / 13 / 20 \\
20\end{array}$ & $\begin{array}{l}\text { 00191-PLO } \\
\text { Extraordinaria }\end{array}$ & $\begin{array}{c}\text { Sin } \\
\text { información } \\
*\end{array}$ & $\begin{array}{c}\text { Sin } \\
\text { información }\end{array}$ & $\begin{array}{l}\text { Levantada por falta } \\
\text { quórum votación }\end{array}$ \\
\hline & $\begin{array}{l}6 / 13 / 20 \\
20\end{array}$ & $\begin{array}{l}\text { 00192-PLO } \\
\text { Extraordinaria }\end{array}$ & 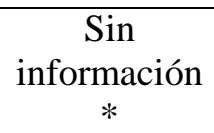 & $\begin{array}{c}\text { Sin } \\
\text { información }\end{array}$ & $\begin{array}{l}\text { Concluido orden del } \\
\text { día }\end{array}$ \\
\hline & $\begin{array}{l}6 / 13 / 20 \\
20\end{array}$ & $\begin{array}{l}\text { 00193-PLO } \\
\text { Extraordinaria }\end{array}$ & $\begin{array}{c}\text { Sin } \\
\text { información } \\
*\end{array}$ & $\begin{array}{c}\text { Sin } \\
\text { información }\end{array}$ & $\begin{array}{l}\text { Concluido orden del } \\
\text { día }\end{array}$ \\
\hline
\end{tabular}

\footnotetext{
* Asunto Covid-19.
} 


Fuente: Agenda del Día Pleno. Senado de la República Dominicana.

http://www.senado.gob.do/senado/SecGralLeg/AgendadelDiaPleno

\section{Conclusiones}

El 19 de marzo de 2020, el Ejecutivo Dominicano declaró el Estado de Emergencia siguiendo los parámetros constitucionales y normativos previstos en la legislación vigente. El Congreso Nacional mantuvo todas sus atribuciones constitucionales para regular y controlar las facultades extraordinarias otorgadas a las autoridades ante la perturbación grave que la Covid19 ocasionó en el orden económico y social (art.10 Ley No. 21-18). La afectación de derechos fundamentales en un contexto de calamidad pública sanitaria, no estimuló sin embargo las labores de diseño de la política pública, ni extremó la fiscalización de acciones del Ejecutivo. No hubo una iniciativa normativa colectiva que reflejara la voz propositiva de la bancada oficialista o de la oposición en el diseño de la política pública de emergencia. Las iniciativas normativas, interpelaciones y autorizaciones presupuestarias reseñadas en este trabajo, muestran que el Poder Legislativo se limitó a ser informado a través de la Comisión Bilateral, y el Pleno de la Cámara ejerció un papel poco beligerante y proactivo. De igual manera, la actividad propositiva del Senado se llevó a cabo a través de Resoluciones unilaterales declarativas de carácter no vinculante.

Este papel menos fiscalizador evidencia su naturaleza de instancia legitimadora de la acción de gobierno en la configuración del equilibrio de poderes. Durante el Estado de Excepción, se hicieron visibles la debilidad de la cohesión legislativa y el individualismo del trabajo parlamentario de unos legisladores en campaña en sus territorios. Como sucediera en otros países del entorno donde sus Presidentes monopolizaron la gestión de la pandemia (MALAMUD Y NÚÑEZ, 2020), la crisis sanitaria en la República Dominicana puso a prueba el liderazgo del candidato oficialista. A pesar del tactismo para alterar el fair play electoral con el toque de queda, la Covid-19 asestó la puntilla final a la debacle de un PLD consumido por la lucha entre facciones y terminó arrollado por los escándalos de corrupción y el descontento social. Su derrota pone fin a un ciclo hegemónico de tres lustros de crecimiento sin redistribución y dominio de las instituciones de control que le ha permitido salir impune de la trama Odebrecht y del despilfarro de sus gobiernos corporativos.

Este trabajo sobre la actividad normativa y fiscalizadora del Congreso Nacional tiene un objetivo descriptivo y de medición del grado de cumplimiento de sus funciones en una coyuntura sin precedentes. La consecución de eventos, asociados al primer Estado de Emergencia, sucediendo al mismo tiempo que se elaboraba este artículo, no han permitido indagar en profundidad otros elementos explicativos del tipo de decisiones o de acuerdos. Por ello, únicamente se han considerado algunos elementos institucionales que describen la habitual dinámica de relaciones entre poderes: el tipo de representación ejercida por los representantes 
o el condicionante de la proximidad de una campaña electoral en dicha actividad. Sin embargo, pese a su lógica descriptiva, la diferenciación temática del tipo de acciones y medidas, la desigual asistencia a los plenos (cumplimiento o no de quorum) y el tipo de votaciones realizadas, ayudan a comprender la forma en que las instituciones representativas afrontaban esta pandemia en la República Dominicana.

\section{Referencias}

ADESA. Atención Primaria en Salud, Situación y Retos en la República Dominicana. Santo Domingo: Alianza por el Derecho a la Salud, 2019.

ALCÁNTARA, Manuel; GARCÍA MONTERO, Mercedes; SÁNCHEZ, Francisco. Funciones, procedimientos y escenarios: Un análisis del Poder Legislativo en América Latina. Salamanca: Ediciones USAL, 2005.

BENITO, Ana Belén ; LOZANO, Wilfredo. "Clientelistic Stability and Institutional Fragility: The Political System in the Dominican Republic (1978-2010)". Latin American Perspectives, v. 39, n. 6, p.198-211, 2012.

BENITO, Ana Belén. "El diputado conseguidor. Representación particularista en el Congreso de la República Dominicana". Revista Española de Ciencia Política, v. 44, p. 151-179, 2017.

BENITO, Ana Belén. "Pactos, alianzas electorales y trashumancias: Patrones de la cooperación estratégica en el sistema de partidos de la República Dominicana". Revista Política y Gobierno, v. 22, n. 1, p.87-123, 2015.

BENITO, Ana Belén.“\#SeFueron en 2020: fin de ciclo y alternancia en la República Dominicana". Revista Estudios de Política Exterior. 2020. Disponible en: https://www.politicaexterior.com/. Aceso en: 1 mar. 2021.

BLONDEL, Jean; THIEBAULT, Jean Louis. The Profession of Government in Western Europe. New York: Palgrave MacMillan., 1971.

CAREY, James. "Ingeniería electoral: ¿Qué nos muestran las investigaciones sobre los efectos anticipados de las reformas electorales?". Reforma del Sistema Electoral Chileno. Santiago: PNUD, 2009.

CARLIN, Ryan; SINGER, Mathew; ZECHMEISTER, Elizabeth. "Introduction to the Latin American voter". In: The Latin American voter, pursuing representation and accountability in challenging context. Ann Arbor: University Michigian Press, p. 1-27, 2015.

GARCÍA MONTERO, Mercedes. "La actividad legislativa en América Latina: sobre el papel reactivo y proactivo de Presidentes y Parlamentos". Lateinamerika Analysen, v. 17, n. 2, 2007. 
JIMÉNEZ-POLANCO, Jacqueline. "La corrupción política en la República Dominicana y la entronización del partido cartel”. Revista RIPS, v. 15, n. 2, p.9-28, 2016.

KITSCHELT, Herbert; HAWKINS, Kirk; LUNA, Juan Pablo; ROSAS, Guillermo; ZECHEMEISTER, Elizabeth. Latin American Party System. Cambridge: University Press, 2010.

MALAMUD, Carlos; NÚÑEZ, Rogelio. "La crisis del coronavirus en América Latina: un incremento del presidencialismo sin red de seguridad". Real Instituto Elcano. Disponible en: http://www.realinstitutoelcano.org,. Aceso en: 1 mar2020.

MARSTEINTREDET, Leiv. "Rendición de cuentas horizontal y preponderancia presidencial en República Dominicana, 1967-2009”. América Latina Hoy, v. 56, p.85-109, 2010.

MARTÍNEZ-GALLARDO, Cecilia.. "Inside the Cabinet. The Influence of Ministers in the Policymaking Process". En How Democracy Works, Washington, p. 119-146, 2010.

MUÑOZ, Juan."Sistema electoral y personalismo de los diputados hondureños". Boletín Datos de Opinión Elites Parlamentarias Latinoamericanas, v. 30, 2011.

OTERO, Patricia; MATEOS, Araceli; RIVAS, Cristina.. "Political parties versus presidents. An analysis of ideological congruence in Latin America". Revista Latinoamericana de Opinión Pública, v. 9, n. ) p.119-150, 2020.

REPÚBLICA DOMINICANA. Estrategia Nacional de Desarrollo 2030. Gaceta Oficial. Ley No.1-2012.

REPÚBLICA DOMINICANA. Ley Orgánica sobre Regulación de los Estados de Excepción. Gaceta Oficial.Ley n. 21/2018.

REPÚBLICA DOMINICANA. Ley que modifica la Ley 506-19 de Presupuesto General del Estado 2020. Gaceta Oficial. Ley n. 68/2020.

REPÚBLICA DOMINICANA. Constitución de la República Dominicana. Gaceta Oficial, 2015.

RePÚBliCA DOMINICANA. Consultoría Jurídica de la Presidencia de la República Dominicana. Disponible en: https://presidencia.gob.do/. Aceso en: 1 mar. 2021.

REPÚBLICA DOMINICANA. Consultoría Jurídica del Poder Ejecutivo. Gobierno de la República Dominicana. Disponible en: http://www.consultoria.gov.do/. Aceso en: 1 mar. 2021.

REPÚBLICA DOMINICANA. Manual de Procedimientos Legislativos. Cámara de Diputados de la República Dominicana, 2017.

REPÚBliCA DOMINICANA. Senado de la República Dominicana. Disponible en: https://senadord.gob.do/actas-de-sesiones/. Aceso en: 1 mar. 2021.

RICO, Guillem; TORCAL, Mariano. "El voto y los elementos psicológicos del anclaje". En El votante dominicano. Ciudadanos y Elecciones en República Dominicana. Santo Domingo: CIDE, FUNGLODE, FLACSO, p.109-136, 2018.

SIL. Sistema de Información Legislativa. Cámara de Diputados de la República Dominicana.. Disponible en: https://www.diputadosrd.gob.do/sil/. Aceso en: 1 mar. 2021. 
SIPEN. Super Intendencia de Pensiones de la República Dominicana. Disponible en: https://www.sipen.gob.do/. Aceso en: 1 mar. 2021.

VANCE CENTER. Corrupción en tiempos de Covid-19: una perspectiva regional sobre contrataciones públicas. Nueya York: Vance Center for International Justice, 2020.

ZOVATTO, Daniel; OROZCO, Jesús. Reforma política y electoral en América Latina 19782007. Ciudad de México: IDEA, 2008. 


\section{ANEXO}

Tabla A.1. Sesión Extraordinaria 00004-2020-PLO del Pleno de la Cámara de Diputados de la República Domicana (3/19/2020)

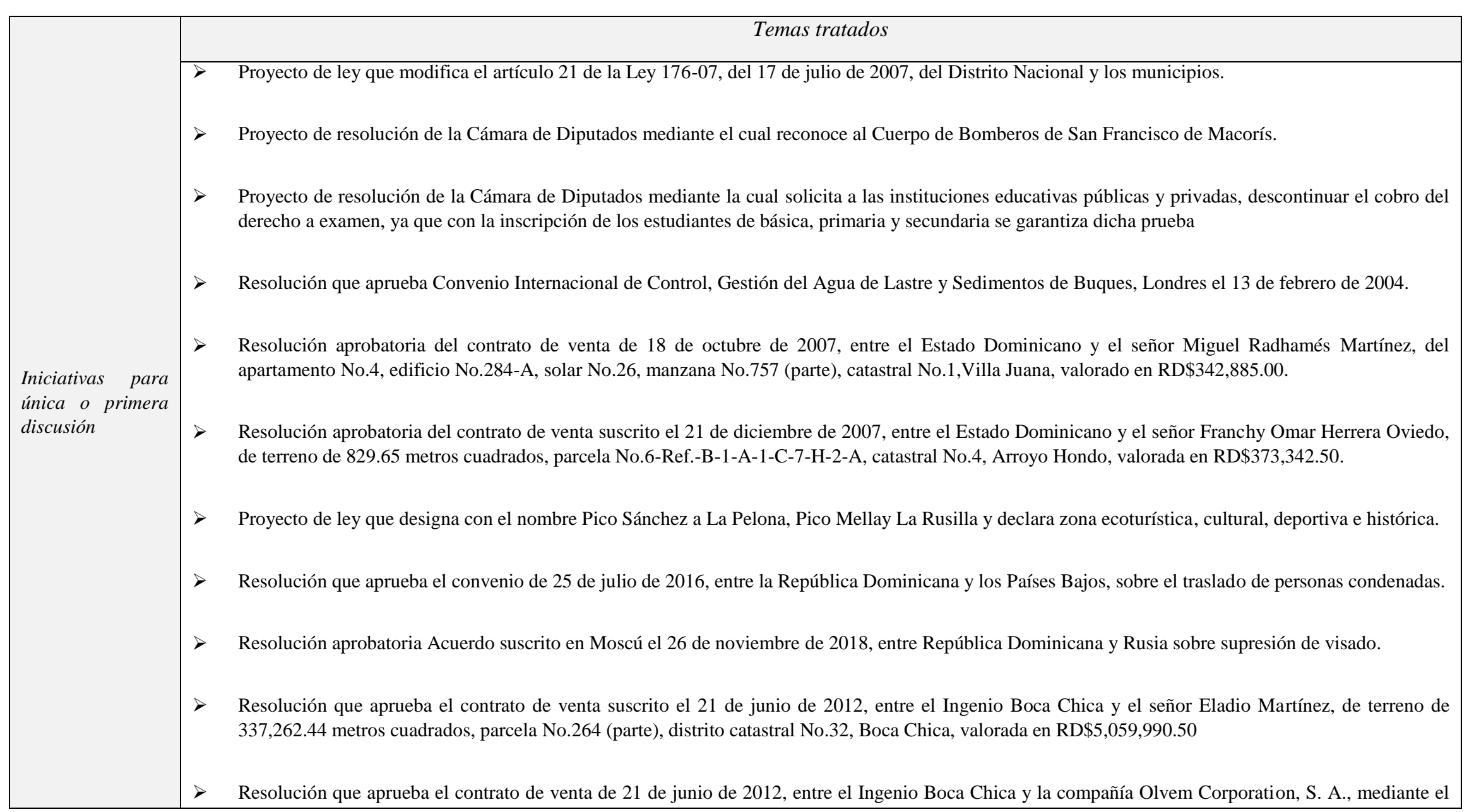




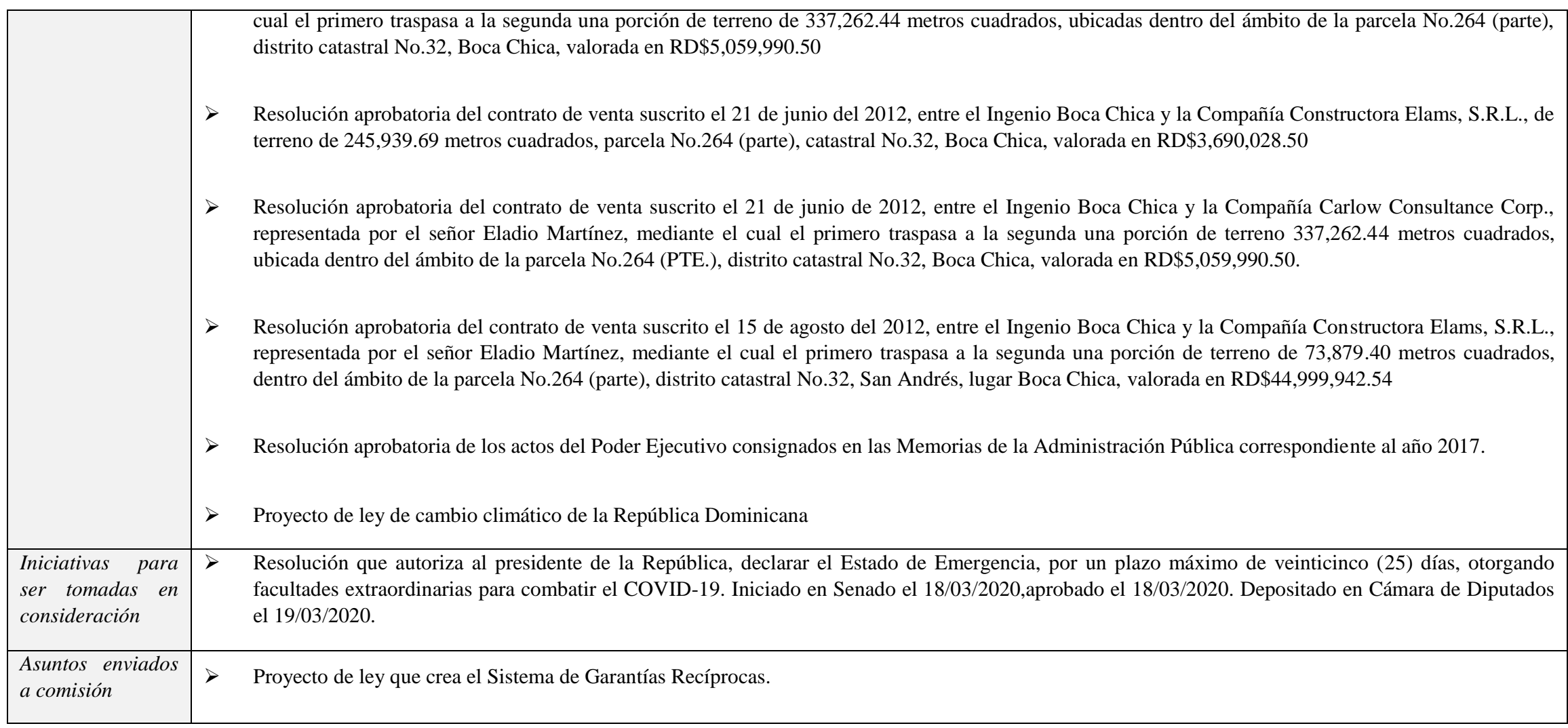

Fuente: Sistema de Información Legislativa (SIL), Cámara de Diputados de la República Dominicana. https://www.diputadosrd.gob.do/sil/ 
Tabla A.2. Sesión Ordinaria 00005-2020-PLO del Pleno de la Cámara de Diputados de la República Domicana (4/09/2020)

\begin{tabular}{|l|l|}
\hline \multicolumn{1}{|c|}{ Temas tratados } \\
\hline Punto único & $\begin{array}{l}\text { Resolución que autoriza al presidente de la República, licenciado Danilo Medina Sánchez, prorrogar hasta por un plazo de veinticinco (25) días, el } \\
\text { estado de emergencia en todo el territorio nacional, declarado en el Decreto presidencial No. 134-20, de fecha 19 de marzo de 2020. (Proponente(s): } \\
\text { Poder Ejecutivo). Iniciado en el Senado el 06/04/2020 y aprobado el 06/04/2020. Depositado en la Cámara de Diputados el 06/04/2020. }\end{array}$ \\
$\begin{array}{l}\text { Sometida a votación la modificación presentada por el diputado Alfredo Pacheco Osorio, que dice: "Modificar el artículo primero para que diga: } \\
\text { Primero: Autorizar al Presidente de la República a que prorrogue el Estado de emergencia en todo el territorio nacional, por un plazo máximo de diecisiete } \\
\text { (17) días, contados a partir del día catorce (14) del mes de abril de 2020 }\end{array}$ \\
\hline
\end{tabular}

Fuente: Sistema de Información Legislativa (SIL), Cámara de Diputados de la República Dominicana. https://www.diputadosrd.gob.do/sil/

Tabla A.3. Sesión Ordinaria 00006-2020-PLO del Pleno de la Cámara de Diputados de la República Domicana (4/28/2020)

\begin{tabular}{|c|c|}
\hline & Temas tratados \\
\hline $\begin{array}{l}\text { Iniciativas para } \\
\text { ser tomadas en } \\
\text { consideración }\end{array}$ & $\begin{array}{l}\text { Resolución que autoriza al presidente de la República prorrogar, hasta por un plazo máximo de veinticinco (25) días, el estado de emergencia en todo el } \\
\text { territorio nacional, declarado en el Decreto presidencial No.134-20, de fecha } 19 \text { de marzo de } 2020 \text { y prorrogado por el Decreto No.148-20, del 13 de } \\
\text { abril de 2020. (Proponente(s): Poder Ejecutivo). Iniciado en el Senado el 26/04/2020 y aprobado el 26/04/2020. Depositado en la Cámara de Diputados } \\
\text { el 27/04/2020. } \\
\text { Sometida a votación la propuesta de modificación presentada por el diputado Alfredo Pacheco Osoria, secundada por los diputados Gustavo Antonio Sánchez } \\
\text { García, Henry Modesto Merán Gil y Máximo Castro, que dice: "Modificar el primer dispositivo para que donde dice: veinticinco (25) días, diga: diecisiete } \\
\text { (17)" }\end{array}$ \\
\hline
\end{tabular}


$>\quad$ Proyecto de ley que permite el retiro único y anticipado de hasta el 30\% de los fondos acumulados por los trabajadores en las administradoras de fondos de pensiones (AFP), para dinamizar la economía familiar en estado de emergencias

Fuente: Sistema de Información Legislativa (SIL), Cámara de Diputados de la República Dominicana. https://www.diputadosrd.gob.do/sil/

Tabla A.4. Sesión Ordinaria 00007-2020-PLO del Pleno de la Cámara de Diputados de la República Domicana (5/14/2020)

\begin{tabular}{|c|c|c|}
\hline & & Temas tratados \\
\hline $\begin{array}{l}\text { Iniciativas para } \\
\text { ser tomadas en } \\
\text { consideración }\end{array}$ & $>$ & $\begin{array}{l}\text { Resolución que autoriza al presidente de la República prorrogar, hasta por un plazo máximo de veinticinco (25) días, el estado de emergencia en todo el } \\
\text { territorio nacional, declarado en el Decreto presidencial No.134-20 del } 19 \text { de marzo de } 2020 \text { y prorrogado por los Decretos No.148-20, del } 13 \text { de abril de } \\
2020 \text {, y No.153-20 de } 30 \text { de abril de 2020. (Proponente(s): Poder Ejecutivo). Iniciado en el Senado el 12/05/2020 y aprobado el 13/05/2020. Depositado } \\
\text { en la Cámara de Diputados el 13/05/2020. } \\
\text { Proyecto de resolución bicameral mediante la cual se solicita al Poder Ejecutivo la adopción de medidas adicionales durante el estado de emergencia } \\
\text { nacional causado por la pandemia del virus Coronavirus o Covid-19. (Proponente(s): Diputado Henry Modesto Merán Gil, Diputado Alfredo Pacheco } \\
\text { Osoria, Diputado Máximo Castro, Diputada Besaida González). }\end{array}$ \\
\hline $\begin{array}{l}\text { Otros } \\
\text { (ternas sustitución } \\
\text { diputados) }\end{array}$ & $>$ & $\begin{array}{l}\text { Comunicación, de fecha } 15 \text { de enero de } 2020 \text {, del presidente del Partido Liberal Reformista (PLR), señor Amable Aristy Castro, mediante la cual remite } \\
\text { la terna para llenar la vacante producida por el fallecimiento del diputado Héctor Ramón Peguero Maldonado. } \\
\text { Comunicación de fecha } 27 \text { de abril de 2020, remitida por el presidente del Partido Revolucionario Dominicano (PRD), ingeniero Miguel Vargas } \\
\text { Maldonado, mediante la cual presenta la terna para llenar vacante producida por la renuncia del señor Santo Ynilcio Ramírez. }\end{array}$ \\
\hline
\end{tabular}




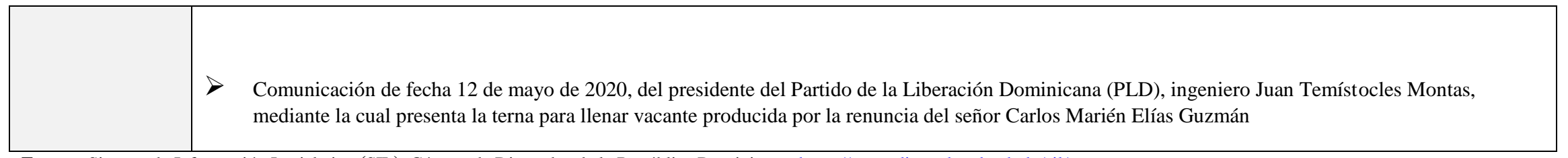

Fuente: Sistema de Información Legislativa (SIL), Cámara de Diputados de la República Dominicana. https://www.diputadosrd.gob.do/sil/

Tabla A.5. Sesión Extraordinaria 00008-2020-PLO del Pleno de la Cámara de Diputados de la República Domicana (5/29/2020)

\begin{tabular}{|l|ll|}
\hline \multicolumn{2}{|l|}{ Temas tratados } \\
\hline $\begin{array}{l}\text { Iniciativas para } \\
\text { ser tomadas en } \\
\text { consideración }\end{array}$ & $\begin{array}{l}\text { Resolución que autoriza al presidente de la República prorrogar, hasta por un plazo máximo de veinticinco (25) días, el estado de emergencia en todo el } \\
\text { territorio nacional, declarado en el Decreto presidencial No.134-20 del 19 de marzo de 2020 y prorrogado por los Decretos No.148-20, del 13 de abril de } \\
\text { 2020, No.153-20 de 30 de abril de 2020 y 160-20 de 17 de mayo de 2020. (Proponente(s): Poder Ejecutivo). Iniciado en el Senado el 28/05/2020 y } \\
\text { aprobado el 28/05/2020. Depositado en la Cámara de Diputados el 28/05/2020. »Número de Iniciativa: 07232-2016-2020-CD }\end{array}$ \\
\hline
\end{tabular}

Fuente: Sistema de Información Legislativa (SIL), Cámara de Diputados de la República Dominicana. https://www.diputadosrd.gob.do/sil/ 
Tabla A.6. Sesión Extraordinaria 00009-2020-PLO del Pleno de la Cámara de Diputados de la República Domicana (5/30/2020)

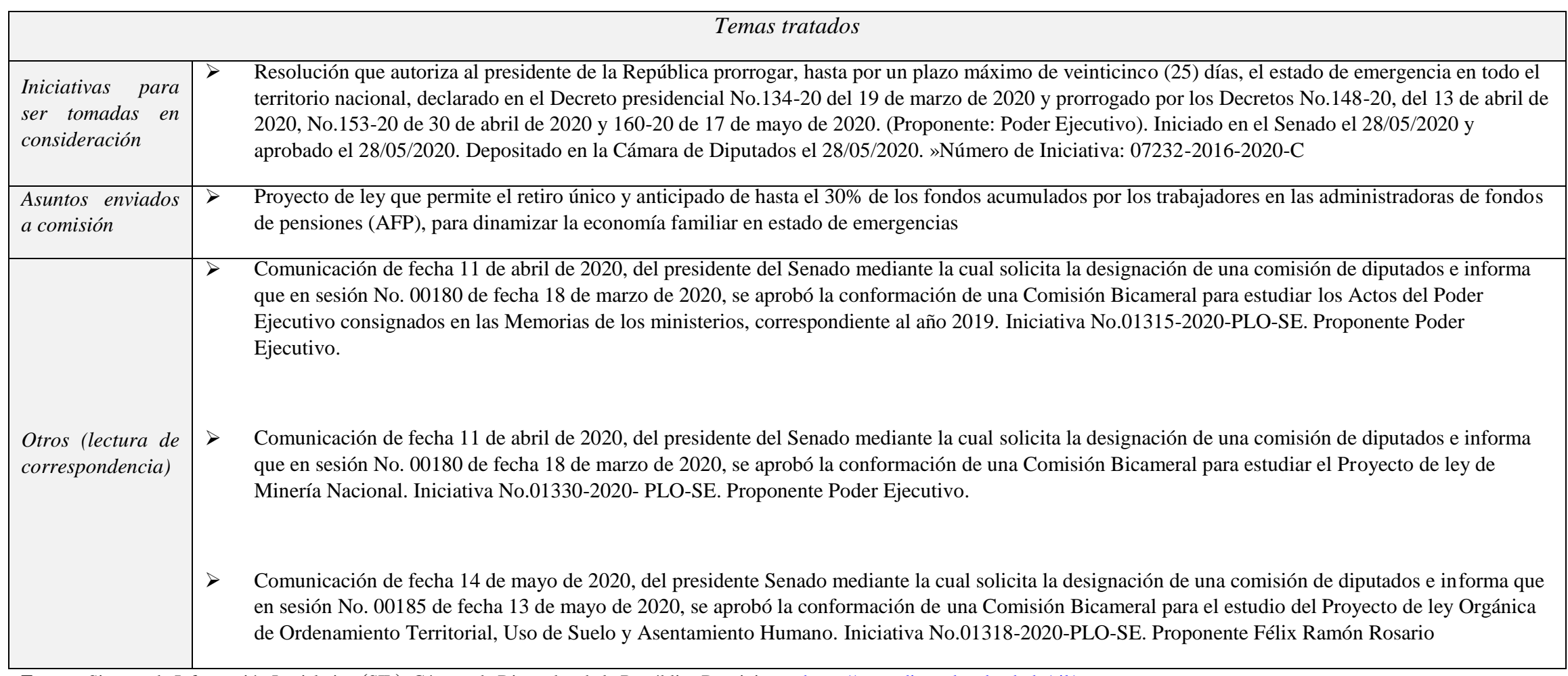

Fuente: Sistema de Información Legislativa (SIL), Cámara de Diputados de la República Dominicana. https://www.diputadosrd.gob.do/sil/ 
Tabla A.7. Sesión Ordinaria 00010-2020-PLO del Pleno de la Cámara de Diputados de la República Domicana (6/10/2020)

\begin{tabular}{|c|c|c|}
\hline & & Temas tratados \\
\hline $\begin{array}{l}\text { Iniciativas para } \\
\text { única o primera } \\
\text { discusión }\end{array}$ & $>$ & Resolución aprobatoria de los actos del Poder Ejecutivo consignados en las Memorias de la Administración Pública correspondiente al año 2017 \\
\hline $\begin{array}{l}\text { Iniciativas para } \\
\text { ser tomadas en } \\
\text { consideración }\end{array}$ & $>$ & $\begin{array}{l}\text { Informe sobre el análisis y la evaluación de la ejecución presupuestaria y la rendición de cuentas generales del Estado del año fiscal 2019, practicada por } \\
\text { la Cámara de Cuentas a cada entidad estatal en cumplimiento al numeral 3, del artículo 250, de la Constitución de la República; y 43, de la Ley } \\
\text { No.10-04, del } 20 \text { de enero de 2004. Depositado el 27/05/2020»Número de Iniciativa: 07229-2016-2020-CD }\end{array}$ \\
\hline
\end{tabular}

Fuente: Sistema de Información Legislativa (SIL), Cámara de Diputados de la República Dominicana. https://www.diputadosrd.gob.do/sil/ 
Tabla A.8. Sesión Extraordinaria 00011-2020-PLO del Pleno de la Cámara de Diputados de la República Domicana (6/12/2020)

\begin{tabular}{|c|c|c|}
\hline \multicolumn{3}{|r|}{ Temas tratados } \\
\hline $\begin{array}{l}\text { Iniciativas para } \\
\text { única o primera } \\
\text { discusión }\end{array}$ & $>$ & Resolución aprobatoria de los actos del Poder Ejecutivo consignados en las Memorias de la Administración Pública correspondiente al año 2017 \\
\hline $\begin{array}{l}\text { Iniciativas para } \\
\text { ser tomadas en } \\
\text { consideración }\end{array}$ & $>$ & $\begin{array}{l}\text { Informe sobre el análisis y la evaluación de la ejecución presupuestaria y la rendición de cuentas generales del Estado del año fiscal } 2019 \text {, practicada por } \\
\text { la Cámara de Cuentas a cada entidad estatal en cumplimiento al numeral 3, del artículo 250, de la Constitución de la República; y 43, de la Ley } \\
\text { No.10-04, del } 20 \text { de enero de 2004. Depositado el 27/05/2020»Número de Iniciativa: 07229-2016-2020-CD }\end{array}$ \\
\hline
\end{tabular}

Fuente: Sistema de Información Legislativa (SIL), Cámara de Diputados de la República Dominicana. https://www.diputadosrd.gob.do/sil// 
Tabla A.9. Sesión Ordinaria 00012-2020-PLO del Pleno de la Cámara de Diputados de la República Domicana (6/18/2020)

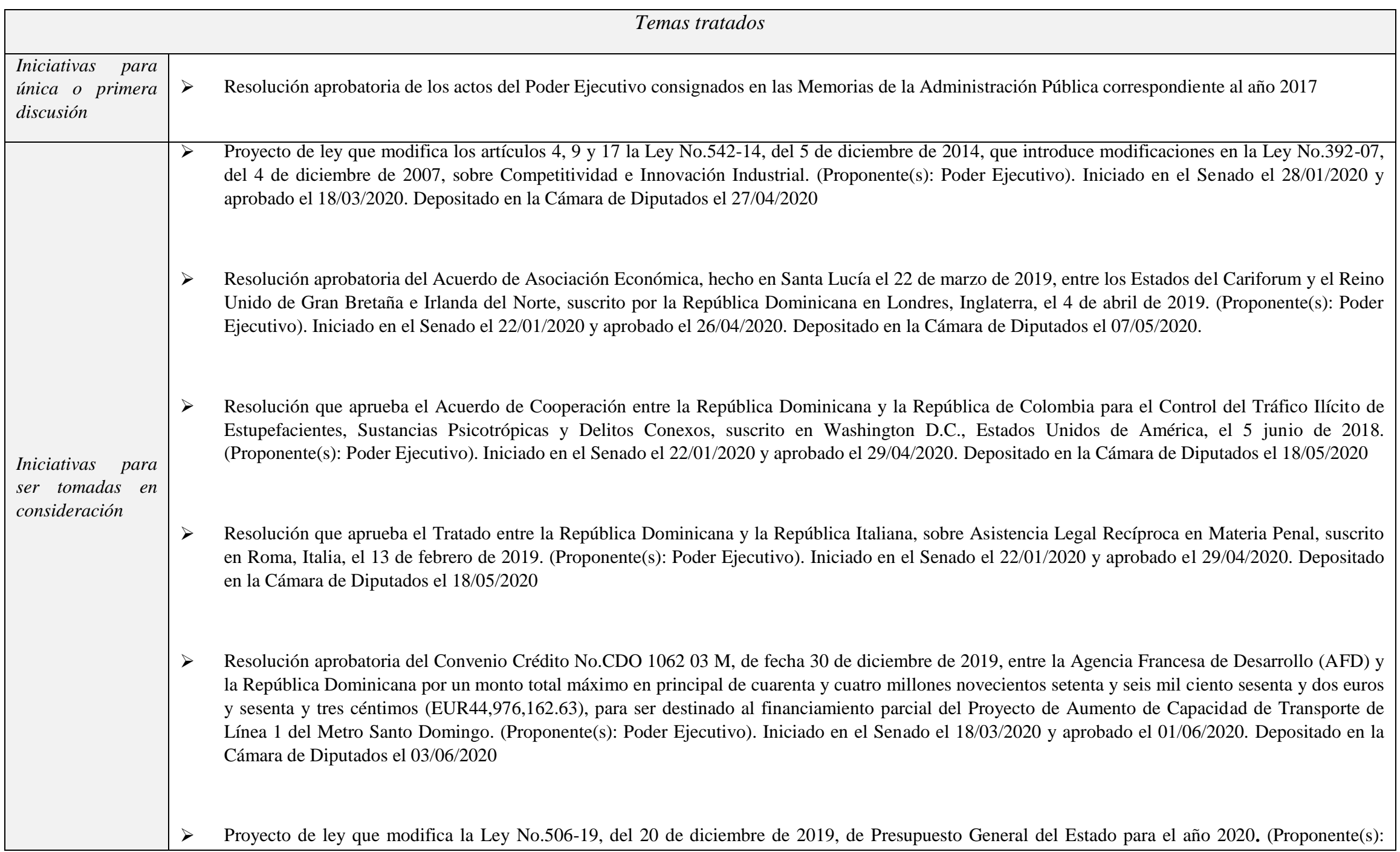




\begin{tabular}{|l|ll|}
\hline & Poder Ejecutivo). Iniciado en el Senado el 13/06/2020 y aprobado el 13/06/2020. Depositado en la Cámara de Diputados 15/06/2020 \\
& $>\quad \begin{array}{l}\text { Resolución aprobatoria para la inclusión de adendum número 3, de fecha 9 de enero de 2020, que modifica el contrato de fideicomiso para la } \\
\text { construcción de viviendas de bajo costo República Dominicana (Fideicomiso VBC RD), de fecha 3 de octubre de 2014, suscrito entre el Estado } \\
\text { dominicano, y la entidad fiduciaria Reservas, S.A. (Proponente(s): Poder Ejecutivo). Iniciado en el Senado el 18/03/2020 y aprobado el 09/06/2020. } \\
\text { Depositado en la Cámara de Diputados el 15/06/2020. }\end{array}$ \\
\hline $\begin{array}{l}\text { Proyectos para } \\
\text { segunda lectura }\end{array}$ & $>\quad \begin{array}{l}\text { Proyecto de ley que permite el retiro único y anticipado de hasta el 30\% de los fondos acumulados por los trabajadores en las administradoras de fondos } \\
\text { de pensiones (AFP), para dinamizar la economía familiar en estado de emergencias }\end{array}$ \\
\hline
\end{tabular}

Fuente: Sistema de Información Legislativa (SIL), Cámara de Diputados de la República Dominicana. https://www.diputadosrd.gob.do/sil/ 
Tabla A.10. Sesión Extraordinaria 00013-2020-PLO del Pleno de la Cámara de Diputados de la República Domicana (6/22/2020)

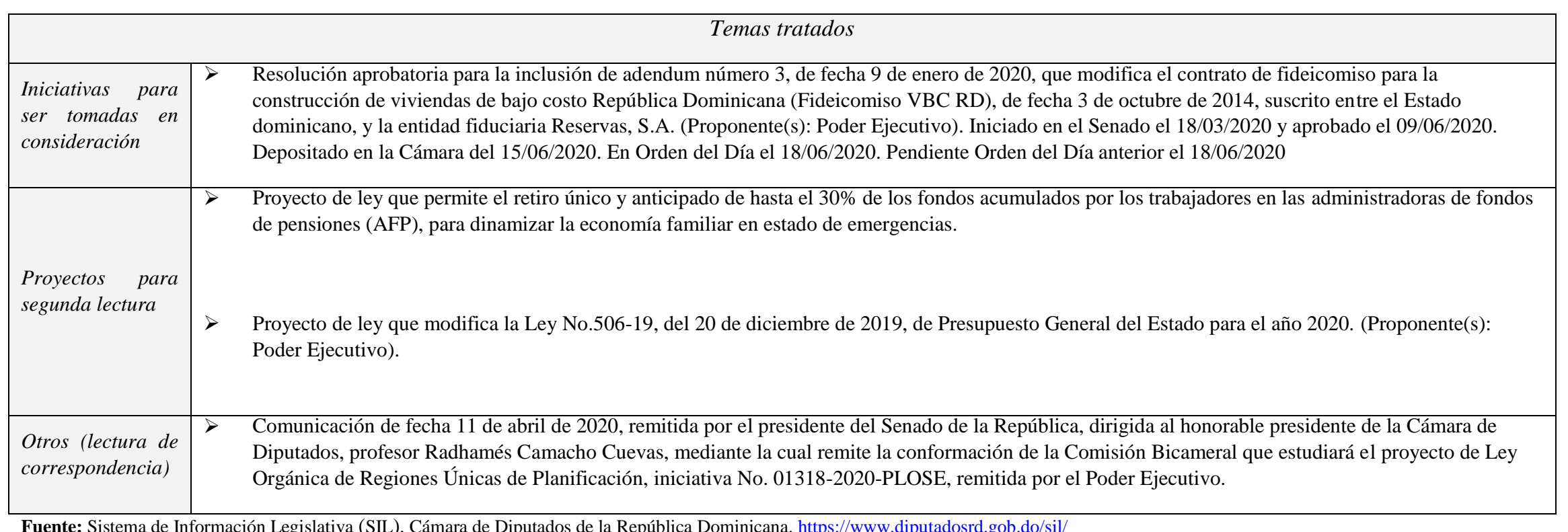


Tabla A.11. Sesión Ordinaria 00180-PLO del Senado de la República Domicana (3/18/2020)

\begin{tabular}{|c|c|c|}
\hline \multicolumn{3}{|r|}{ Temas tratados } \\
\hline Correspondencia & $>$ & $\begin{array}{l}\text { Presidente Cámara de Diputados informa la integración de la Comisión Bicameral que estudiará el proyecto de Ley de Agua. } \\
\text { Presidente Cámara de Diputados informa conformación Comisión Bicameral que estudiará el proyecto de Ley Servicios Vigilancia y Seguridad Privada. } \\
\text { Presidente Cámara de Diputados remite la resolución no.00797, del } 6 \text { de febrero de 2020, con la escogencia de Milagros Pilar Corniel como diputada. }\end{array}$ \\
\hline $\begin{array}{l}\text { Iniciativas del } \\
\text { Ejecutivo a tomar } \\
\text { en consideración }\end{array}$ & $>$ & $\begin{array}{l}\text { Addendum al contrato de fideicomiso para la construcción de viviendas de bajo costo en República Dominicana. } \\
\text { Actos del Poder Ejecutivo consignados en las Memorias de los Ministerios correspondiente al año } 2019 . \\
\text { Proyecto de ley orgánica de regiones únicas de planificación. } \\
\text { Proyecto de ley de minería nacional. } \\
\text { Proyecto de modificación de la Ley núm.167-07 de Rcapitalización del Banco central de la República Dominicana. } \\
\text { Ratificación del nombramiento diplomatico del señor Fausto Marino Mendoza Rodríguez, como embajador extraordinario y pleniponteciario en Panamá. } \\
\text { Ratificación del nombramiento diplomático del señor Víctor Manuel Grimaldi Céspedes, como embajador extraordinario y plenipotenciario en Suecia. } \\
\text { Convenio de crèdito nùm.cdo } 106203 \text { m, suscrito el } 30 \text { de diciembre de 2019, entre la Repùblica Dominicana y la Agencia Francesa de dDesarrollo } \\
\text { (AFD) para el financiamiento de proyecto de aumento de capacidad de transporte de la linea } 1 \text { del metro de Santo Domingo. } \\
\text { Resolución Bicameral mediante la cual se solicita declarar el Estado de Emergencia en todo el territorial nacional. }\end{array}$ \\
\hline
\end{tabular}




\begin{tabular}{|c|c|c|}
\hline $\begin{array}{l}\text { Iniciativas de } \\
\text { senadores a tomar } \\
\text { en consideración }\end{array}$ & $>$ & $\begin{array}{l}\text { Proyecto de ley que declara el día } 21 \text { de diciembre de cada año como "Día nacional del Defensor Público". } \\
\text { Proyecto de ley que regula el indulto. } \\
\text { Proyecto de ley orgánica de libertad de reunión. } \\
\text { Proyecto de ley sobre divorcio. } \\
\text { Proyecto de ley sobre responsabilidad civil de los funcionarios públicos. } \\
\text { Proyecto de ley sobre ejecución de sentencias del tribunal constitucional de la república dominicana. } \\
\text { Proyecto de ley que crea el colegio de administradores dominicano. } \\
\text { Proyecto de ley mediante el cual se crea la dirección general de representación legal de los derechos de la víctima. } \\
\text { Proyecto de ley sobre registro y mantenimiento de infraestructuras públicas. } \\
\text { Proyecto de ley de fomento de la cultura de paz en todos los niveles del sistema educativo dominicano. } \\
\text { Proyecto de ley orgánica de seguridad y defensa nacional. } \\
\text { Proyecto de ley de régimen jurídico de la propiedad de las tierras fronterizas. } \\
\text { Proyecto de ley que regula la vigilancia y seguridad privada. } \\
\text { Proyecto de ley que crea el boletín oficial del estado para la publicación de leyes modificadas. } \\
\text { Proyecto de ley que modifica la ley } 87-01 \text {, que crea el Sistema Dominicano de Seguridad Social. }\end{array}$ \\
\hline $\begin{array}{l}\text { Iniciativas } \\
\text { observadas por el } \\
\text { Ejecutivo }\end{array}$ & $>$ & $\begin{array}{l}\text { Observación del Ejecutivo a la ley de educación ambiental de la República Dominicana. } \\
\text { Observación del Ejecutivo a la ley que regula el sistema penitenciario y correccional en la República Dominicana. }\end{array}$ \\
\hline $\begin{array}{l}\text { Proyectos de ley } \\
\text { segunda discusión }\end{array}$ & $>$ & Proyecto de ley que modifica la Ley núm. 542-14, que introduce modificaciones a la Ley núm. 392-07, sobre Competitividad e Innovación Industrial. \\
\hline $\begin{array}{l}\text { Iniciativas } \\
\text { primera discusión }\end{array}$ & $>$ & $\begin{array}{l}\text { Proyecto de ley sobre la devolución del impuesto a la transferencia de bienes industrializados y servicios (ITBIS) al turista extranjero. } \\
\text { Ratificación del nombramiento diplomatico del señor Fausto Marino Mendoza Rodríguez, como embajador extraordinario y pleniponteciario en Panamá. } \\
\text { Ratificación del nombramiento diplomático del señor Víctor Manuel Grimaldi Céspedes, como embajador extraordinario y plenipotenciario en Suecia. }\end{array}$ \\
\hline
\end{tabular}


Resolución Bicameral mediante la cual se solicita declarar en Estado de Emergencia en todo el territorial nacional.

Fuente: Agenda del Día Pleno. Senado de la República Dominicana. http://www.senado.gob.do/senado/SecGralLeg/AgendadelDiaPleno

\section{Tabla A.12. Sesión Ordinaria 00181-PLO del Senado de la República Domicana (4/06/2020)}

\begin{tabular}{|c|c|c|}
\hline \multicolumn{3}{|r|}{ Temas tratados } \\
\hline Correspondencia & $>$ & El Poder Ejecutivo remite el primer Informe relativo al Estado de Emergencia \\
\hline $\begin{array}{l}\text { Iniciativas del } \\
\text { Ejecutivo a tomar } \\
\text { en consideración }\end{array}$ & $>$ & Solicitud de prórroga a la resolución del Congreso no.62-20 que autorizó al Presidente declarar el Estado de Emergencia por veinticinco (25) días. \\
\hline $\begin{array}{l}\text { Iniciativas de } \\
\text { senadores a tomar } \\
\text { en consideración }\end{array}$ & $>$ & $\begin{array}{l}\text { Ley que agrega el artìculo 59-bis, a la Ley } 87-01 \text { que crea el Sistema Dominicano de la Seguridad Social, para que en caso de Estado de Excepciòn, el } \\
\text { trabajador pueda acceder hasta un } 20 \% \text { de los recursos acumulados en su fondo de pensiòn individual. } \\
\text { Proyecto de ley que modifica los artìculos } 20 \text { y } 32 \text { de la Ley Orgànica no.21-18, que regula los Estados de Excepciòn. } \\
\text { Resolución que solicita al Presidente de la Republica proponer ante la Asamblea General de la Organización de las Naciones Unidas (ONU), la creación } \\
\text { de un fondo que permita contratar el desarrollo de vacunas y medicamentos contra epidemias, pandemias y endemias. }\end{array}$ \\
\hline $\begin{array}{l}\text { Iniciativas } \\
\text { liberadas de } \\
\text { trámites }\end{array}$ & $>$ & Solicitud de prórroga a la resolución del Congreso no.62-20 que autorizó al Presidente declarar el estado de emergencia por veinticinco (25) días. \\
\hline
\end{tabular}

Fuente: Agenda del Día Pleno. Senado de la República Dominicana. http://www.senado.gob.do/senado/SecGralLeg/AgendadelDiaPleno 
Tabla A.13. Sesión Extraordinaria 00182-PLO del Senado de la República Domicana (4/11/2020)

\begin{tabular}{|l|ll|}
\hline \multicolumn{2}{|c|}{ Temas tratados } \\
\hline $\begin{array}{l}\text { Proyectos de Ley } \\
\text { con } \\
\begin{array}{l}\text { modificaciones } \\
\text { devueltos por la } \\
\text { Cámara }\end{array}\end{array} \quad \begin{array}{l}\text { Solicitud de prórroga a la resolución del Congreso Nacional no.62-20 que autorizó al Presidente de la República, declarar el Estado de Emergencia en } \\
\text { todo el territorio nacional por veinticinco (25) días. Título modificado: Resolución que autoriza al Presidente de la República prorrogar, hasta un plazo } \\
\text { máximo de diecisiete (17) días, el Estado de Emergencia en todo el territorio nacional, declarado en el decreto no.134-20. }\end{array}$ \\
\hline
\end{tabular}

Fuente: Agenda del Día Pleno. Senado de la República Dominicana. http://www.senado.gob.do/senado/SecGralLeg/AgendadelDiaPleno

Tabla A.14. Sesión Ordinaria 00183-PLO del Senado de la República Domicana (4/26/2020)

\begin{tabular}{|c|c|c|}
\hline \multicolumn{3}{|r|}{ Temas tratados } \\
\hline Correspondencia & $>$ & Comisión Bicameral de Seguimiento al Estado de Emergencia remite el segundo Informe del Ejecutivo. \\
\hline $\begin{array}{l}\text { Iniciativas del } \\
\text { Ejecutivo a tomar } \\
\text { en consideración }\end{array}$ & $>$ & Solicitud de prórroga del Estado de Emergencia mediante el decreto no.134-20 y prorrogado por el decreto 148-20, por veinticinco (25) días \\
\hline $\begin{array}{l}\text { Iniciativas de } \\
\text { senadores a tomar } \\
\text { en consideración }\end{array}$ & $\begin{array}{l}> \\
> \\
>\end{array}$ & $\begin{array}{l}\text { Resolución que reconoce la labor de médicos, enfermeras y personal de apoyo en hospitales y clínicas, así como de militares y policías de la República } \\
\text { Dominicana ante la pandemia Covid } 19 . \\
\text { Resolución que solicita al Presidente de la República la creación de un fondo de asistencia escolar destinado a ayudar a los padres de alumnos de } \\
\text { colegios privados que le han sido suspendidos sus contratos de trabajo como consecuencia de las medidas implementadas por el Gobierno. } \\
\text { Resolución mediante la cual se solicita al Poder Ejecutivo la adopción de medidas adicionales durante el Estado de Emergencia nacional causado por la } \\
\text { pandemia Covid-19) } \\
\text { Resolución que sugiere al Presidente de la República que el Seguro Nacional de Salud (SENASA), sea incluido mediante decreto dentro de las } \\
\text { instituciones que pueden licitar en el marco del Estado de Emergencia. }\end{array}$ \\
\hline
\end{tabular}




\begin{tabular}{|c|c|c|}
\hline \multirow{3}{*}{$\begin{array}{l}\text { Iniciativas } \\
\text { liberadas de } \\
\text { trámites }\end{array}$} & $>$ & $\begin{array}{l}\text { Solicitud de prórroga del Estado de Emergencia declarado en todo el territorio nacional mediante el decreto no.134-20 y prorrogado por el decreto } \\
148-20 \text {, por veinticinco (25) días. }\end{array}$ \\
\hline & $>$ & $\begin{array}{l}\text { Resolución que reconoce la labor de médicos, enfermeras y personal de apoyo en hospitales y clínicas, así como de militares y policías de la República } \\
\text { Dominicana ante la pandemia Covid-19. }\end{array}$ \\
\hline & $>$ & Acuerdo de asociación económica entre los estados del Cariforo y el Reino Unido suscrito en Londres, el 4 de abril de 2019 \\
\hline
\end{tabular}

Fuente: Agenda del Día Pleno. Senado de la República Dominicana. http://www.senado.gob.do/senado/SecGralLeg/AgendadelDiaPleno

Tabla A.15. Sesión Extraordinaria 00184-PLO del Senado de la República Domicana (4/29/2020)

\begin{tabular}{|l|l|l|}
\hline \multicolumn{2}{|l}{ Temas tratados } \\
\hline $\begin{array}{l}\text { Proyectos de ley } \\
\text { con } \\
\begin{array}{l}\text { modificaciones } \\
\text { devueltos por la } \\
\text { Cámara }\end{array}\end{array}$ & $>$ & $\begin{array}{l}\text { Resolución que autoriza al Presidente de la República prorrogar, hasta por un plazo máximo de 25 días, el Estado de Emergencia en todo el territorio } \\
\text { nacional, declarado en el decreto presidencial }\end{array}$ \\
\hline $\begin{array}{l}\text { Iniciativas única } \\
\text { discusión }\end{array}$ & $>$ & $\begin{array}{l}\text { Acuerdo de cooperación entre la República Dominicana y la República de Colombia para el control del tráfico ilícito de estupefacientes, sustancias } \\
\text { psicotrópicas y delitos conexos, suscrito el } 5 \text { de junio de 2018. }\end{array}$ \\
& $\begin{array}{l}\text { Tratado entre la República Dominicana y la República Italiana sobre asistencia legal recíproca en materia penal, firmado en roma, el 13 de febrero de } \\
2019 .\end{array}$ \\
\hline
\end{tabular}

Fuente: Agenda del Día Pleno. Senado de la República Dominicana. http://www.senado.gob.do/senado/SecGralLeg/AgendadelDiaPleno 
Tabla A.16. Sesión Extraordinaria 00185-PLO del Senado de la República Domicana (5/13/2020)

\begin{tabular}{|c|c|c|}
\hline \multicolumn{3}{|r|}{ Temas tratados } \\
\hline Correspondencia & $>$ & $\begin{array}{l}\text { Gobernador del Banco Central remite el informe sobre el comportamiento del índice de precios al consumidor (IPC) del mes de febrero } 2020 . \\
\text { Ministro de Hacienda remite el informe de deuda pública del trimestre enero-marzo } 2020 .\end{array}$ \\
\hline $\begin{array}{l}\text { Iniciativas del } \\
\text { Ejecutivo a tomar } \\
\text { en consideración }\end{array}$ & $>$ & $\begin{array}{l}\text { Tratado de extradicción entre la República Dominicana y la República del Perú. } \\
\text { Auerdo entre el Gobierno de la República Dominicana y el Gobierno de la República de Serbia sobre la exención de visas para portadores de pasaportes } \\
\text { diplomáticos y oficiales. } \\
\text { Solicitud de prórroga, por un plazo de veinticinco (25) días, del Estado de Emergencia declarado en todo el territorio nacional mediante el decreto } \\
\text { no.134-20 y prorrogado por los decretos nos. 148-20 y 153-20. }\end{array}$ \\
\hline $\begin{array}{l}\text { Iniciativas de la } \\
\text { Cámara a tomar } \\
\text { en consideración }\end{array}$ & $>$ & $\begin{array}{l}\text { Proyecto de ley que deroga el artículo } 165 \text { de la ley no.821 de organización judicial, del } 21 \text { de noviembre de } 1927 \text {, y la ley no.1021 del } 16 \text { de octubre de } \\
1935 .\end{array}$ \\
\hline $\begin{array}{l}\text { Iniciativas de los } \\
\text { senadores a tomar } \\
\text { en consideración }\end{array}$ & $\begin{array}{l}D \\
D \\
D \\
D \\
D \\
D \\
D \\
D \\
D\end{array}$ & $\begin{array}{l}\text { Proyecto de ley que crea el sistema de apoyo integral para la prevención, sanción y erradicación de la violencia contra las mujeres. } \\
\text { Proyecto de ley que crea el fondo para el desarrollo e innovación del emprendimiento(fodine). } \\
\text { Proyecto de ley orgánica sobre expropiación de bienes inmuebles por declaratoria de utilidad pública o interés social. } \\
\text { Proyecto de ley de participación igualitaria entre hombres y las mujeres en la Administración Pública y Poderes del Estado. } \\
\text { Proyecto de ley de estímulo a la inversión, desarrollo e innovación tecnológicas. } \\
\text { Proyecto de ley orgánica de ordenamiento territorial, uso de suelo y asentamiento humano. } \\
\text { Proyecto de ley sobre la prohibición de discriminación del trabajo y ocupación por la edad. } \\
\text { Proyecto de ley general del sector agropecuario y el desarrollo rural. } \\
\text { Proyecto de ley del trabajo doméstico en la República Dominicana. }\end{array}$ \\
\hline
\end{tabular}




\begin{tabular}{|l|ll|}
\hline & $>$ & $\begin{array}{l}\text { Proyecto de ley que declara el municipio de Miches, provincia de El Seibo "Polo Turístico". } \\
\text { Resolución de reconocimiento al músico vegano Ramón Andrés García Sánchez. }\end{array}$ \\
\hline $\begin{array}{l}\text { Proyectos de ley } \\
\text { segunda discusión }\end{array}$ & $>$ & Proyecto de ley sobre la devolución del impuesto a la transferencia de bienes industrializados y servicios (ITBIS) al turista extranjero. \\
\hline $\begin{array}{l}\text { Iniciativas } \\
\text { liberadas de } \\
\text { trámites }\end{array}$ & $>$ & $\begin{array}{l}\text { Solicitud de prórroga, por un plazo de veinticinco (25) días, del Estado de Emergencia declarado en todo el territorio nacional mediante el decreto } \\
\text { no.134-20 y prorrogado por los decretos nos. 148-20 y 153-20 }\end{array}$ \\
\hline
\end{tabular}

Fuente: Agenda del Día Pleno. Senado de la República Dominicana. http://www.senado.gob.do/senado/SecGralLeg/AgendadelDiaPleno

Tabla A.17. Sesión Extraordinaria 00186-PLO del Senado de la República Domicana (5/15/2020)

\begin{tabular}{|l|lll|}
\hline \multicolumn{2}{|c|}{ Temas tratados } \\
\hline Correspondencia & $>$ & $\begin{array}{l}\text { El senador Luis René Canaán Rojas presidente de la Comisíon Bicameral de Seguimiento del Estado de Emergencia solicita ésta sea desapoderada de las } \\
\text { resoluciones 01346 Comisión de Hacienda y 01348 Comisión de Salud. }\end{array}$ \\
& $>$ & $\begin{array}{l}\text { La Cámara de Cuentas, remite el informe sobre el análisis y la evaluación de la ejecución presupuestaria y la rendición de cuentas generales del Estado } \\
\text { del año fiscal } 2019 .\end{array}$ \\
$\begin{array}{l}\text { Iniciativas de } \\
\text { senadores a tomar } \\
\text { en consideración }\end{array}$ & $>$ & $\begin{array}{l}\text { Proyecto de ley que modifica la Ley no. 172-13 que tiene por objeto la protección integral de los datos personales asentados en archivos, registros } \\
\text { públicos, bancos de datos u otros medios técnicos de tratamiento de datos destinados a dar informes, sean estos públicos o privados. }\end{array}$ \\
& $>$ & $\begin{array}{l}\text { Proyecto de ley Orgánica de la Administración Local. } \\
\text { Proyecto de ley que descentraliza la administración del agua potable y el alcantarillado en la República Dominicana. }\end{array}$ \\
& $>$ & Proyecto de ley que declara el carnaval de Montecristi como patrimonio folclórico de la nación dominicana.
\end{tabular}




\begin{tabular}{|c|c|c|}
\hline & $>$ & $\begin{array}{l}\text { Proyecto de ley que designa con el nombre de dr. Mario Mignolio Pujols Colón, el palacio de justicia de la provincia San José de Ocoa. } \\
\text { Proyecto de ley que modifica los límites territoriales del Parque Nacional los Haitises. } \\
\text { Proyecto de ley mediante el cual se designa con el nombre “Juan Ramón Díaz” el Liceo Secundario de Yerba Buena, provincia Hato Mayor. } \\
\text { Resolución de reconocimiento al músico vegano Francisco Furgos Rosario (Paquito). } \\
\text { Proyecto de ley mediante el cual se concede un aumento de pensión de rd } \$ 7,500.00 \text { a la suma de rd } \$ 20,000.00 \text { mensuales la pensión del Estado que } \\
\text { recibe la señora e Eridania Margarita Reyes Morel de Núñez. } \\
\text { Proyecto de ley que establece un tope a las exoneraciones de vehiculos de los legisladores. }\end{array}$ \\
\hline $\begin{array}{l}\text { Proyectos de Ley } \\
\text { con } \\
\text { modificaciones } \\
\text { devueltos por } \\
\text { Cámara de } \\
\text { Diputados }\end{array}$ & $>$ & $\begin{array}{l}\text { Solicitud de prórroga, por un plazo de veinticinco (25) días, del Estado de Emergencia declarado en todo el territorio nacional mediante el decreto } \\
\text { no.134-20 y prorrogado por los decretos nos. 148-20 y 153-20. Título modificado: resolución que autoriza al Presidente prorrogar, hasta un plazo } \\
\text { máximo de quince (15) días }\end{array}$ \\
\hline $\begin{array}{l}\text { Iniciativas única } \\
\text { discusión }\end{array}$ & $>$ & $\begin{array}{l}\text { Resolución que solicita al excelentísimo señor Presidente de la Republica proponer ante la Asamblea General de la Organización de las Naciones Unidas } \\
\text { (ONU), la creación de un fondo que permita contratar el desarrollo de vacunas y medicamentos contra epidemias, pandemias y endemias. }\end{array}$ \\
\hline $\begin{array}{l}\text { Iniciativa para } \\
\text { primera discuión }\end{array}$ & & $\begin{array}{l}\text { Proyecto de ley que declara la procesión de la divina pastora como patrimonio cultural inmaterial de la nación dominicana y la iglesia divina pastora } \\
\text { como patrimonio monumental. }\end{array}$ \\
\hline
\end{tabular}

Fuente: Agenda del Día Pleno. Senado de la República Dominicana. http://www.senado.gob.do/senado/SecGralLeg/AgendadelDiaPleno 
Tabla A.18. Sesión Extraordinaria 00187-PLO del Senado de la República Domicana (5/28/2020)

\begin{tabular}{|c|c|}
\hline \multicolumn{2}{|r|}{ Temas tratados } \\
\hline Correspondencia & $>$ Comisíon Bicameral de Seguimiento al Estado de Emergencia, remite el cuarto Informe del Ejecutivo. \\
\hline $\begin{array}{l}\text { Iniciativas del } \\
\text { Ejecutivo a tomar } \\
\text { en consideración }\end{array}$ & $\begin{array}{l}\text { Solicitud de prórroga por un plazo de veinticinco (25) días, el Estado de Emergencia declarado en todo el territorio nacional mediante los decretos } \\
\text { nos.148-20 y 160-20. }\end{array}$ \\
\hline $\begin{array}{l}\text { Iniciativas de } \\
\text { senadores a tomar } \\
\text { en consideración }\end{array}$ & $\begin{array}{l}\text { Proyecto de ley que designa con el nombre de Silvano Reynoso Rojas, el hospital general de Villa Isabela, Puerto Plata. } \\
>\quad \text { Proyecto de ley que declara el museo judio de Sosúa como patrimonio cultural de la nacion dominicana. } \\
>\quad \text { Proyecto de ley mediante el cual se eliminan las exoneraciones de impuestos en la compra de automoviles por parte de los legisladores. } \\
>\quad \text { Proyecto de ley que dispone la instalación de fuentes de energia renovable en edificios públicos y privados. } \\
>\quad \text { Proyecto de ley de integridad en la función pública, transparencia y penalización de acciones corruptas. }\end{array}$ \\
\hline $\begin{array}{l}\text { Lectura informes } \\
\text { de gestión }\end{array}$ & $>$ Informe de gestión para dar seguimiento al Estado de Emergencia Nacional declarado por el Presidente de la República, \\
\hline $\begin{array}{l}\text { Iniciativas } \\
\text { liberadas } \\
\text { trámites }\end{array}$ & Solicitud de prórroga por un plazo de veinticinco (25) días, el Estado de Emergencia declarado en todo el territorio nacional \\
\hline
\end{tabular}

Fuente: Agenda del Día Pleno. Senado de la República Dominicana. http://www.senado.gob.do/senado/SecGralLeg/AgendadelDiaPleno 
Tabla A.19. Sesión Extraordinaria 00188-PLO del Senado de la República Domicana (6/01/2020)

\begin{tabular}{|c|c|}
\hline \multicolumn{2}{|r|}{ Temas tratados } \\
\hline Correspondencia & $>\quad$ Comisíon Bicameral de Seguimiento al Estado de Emergencia, remite el quinto Informe del Ejecutivo. \\
\hline $\begin{array}{l}\text { Lectura informes } \\
\text { comisiones }\end{array}$ & $\begin{array}{l}\text { Addendum número } 3 \text { al contrato de fideicomiso para la construcción de viviendas de bajo costo en República Dominicana } \\
\text { Proyecto de ley de Agua de la República Dominicana. }\end{array}$ \\
\hline $\begin{array}{l}\text { Proyectos de } \\
\text { con } \\
\text { modificaciones } \\
\text { devuelto por } \\
\text { Cámara de } \\
\text { Diputados }\end{array}$ & $\begin{array}{l}\text { Solicitud de prórroga por un plazo de veinticinco (25) días, el estado de emergencia declarado en todo el territorio nacional mediante los decretos } \\
\text { nos.148-20 y 160-20. Título modificado: resolución que autoriza al presidente de la República prorrogar, hasta un plazo máximo de doce (12) días, el } \\
\text { estado de emergencia en todo el territorio nacional }\end{array}$ \\
\hline $\begin{array}{l}\text { Proyectos de Ley } \\
\text { segunda discusión }\end{array}$ & $\begin{array}{l}\text { Proyecto de Ley que declara la procesión de la divina pastora como patrimonio cultural inmaterial de la nación dominicana y la iglesia divina pastora } \\
\text { como patrimonio monumental. }\end{array}$ \\
\hline $\begin{array}{l}\text { Iniciativas única } \\
\text { discusión }\end{array}$ & $\begin{array}{l}\text { Convenio de crèdito suscrito el } 30 \text { de diciembre de 2019, entre la Repùblica Dominicana y la Agencia Francesa de desarrollo para el financiamiento de } \\
\text { proyecto de aumento de capacidad de transporte de la linea } 1 \text { del metro de Santo Somingo. }\end{array}$ \\
\hline $\begin{array}{l}\text { Iniciativa para } \\
\text { primera discuión }\end{array}$ & $>\quad$ Proyecto de ley de agua de la Republica Dominicana. \\
\hline
\end{tabular}

Fuente: Agenda del Día Pleno. Senado de la República Dominicana. http://www.senado.gob.do/senado/SecGralLeg/AgendadelDiaPleno 
Tabla A.20. Sesión Extraordinaria 00192-PLO del Senado de la República Domicana (6/13/2020)

Temas tratados

\begin{tabular}{l|lcl}
\hline Correspondencia & $>$ & La Comisíon Bicameral de Seguimiento al Estado de Emergencia, remite el sexto Informe del Ejecutivo. \\
\hline $\begin{array}{l}\text { Iniciativas del } \\
\begin{array}{l}\text { Ejecutivo a tomar } \\
\text { en consideración }\end{array}\end{array}$ & $>\quad$ Proyecto que modifica la Ley núm. 506-19 que aprueba el Presupuesto General del Estado correspondiente al año 2020. \\
\hline
\end{tabular}

Fuente: Agenda del Día Pleno. Senado de la República Dominicana. http://www.senado.gob.do/senado/SecGralLeg/AgendadelDiaPleno

\section{Tabla A.21. Sesión Extraordinaria 00193-PLO del Senado de la República Domicana (6/13/2020)}

\begin{tabular}{|l|lcl|}
\hline \multicolumn{2}{|c|}{ Temas tratados } \\
\hline $\begin{array}{l}\text { Proyectos para } \\
\text { segunda lectura }\end{array}$ & $>\quad$ Proyecto que modifica la Ley núm. 506-19 que aprueba el Presupuesto General del Estado correspondiente al año 2020. \\
\hline
\end{tabular}

Fuente: Agenda del Día Pleno. Senado de la República Dominicana. http://www.senado.gob.do/senado/SecGralLeg/AgendadelDiaPleno 